\title{
Let's walk! Age reattribution and physical activity among older Hispanic/Latino adults: results from the ¡Caminemos! Randomized trial
}

Lissette M. Piedra $^{1 *}$ (D), Flavia C. D. Andrade², Rosalba Hernandez ${ }^{1}$, Laura Trejo ${ }^{3}$, Thomas R. Prohaska ${ }^{4}$ and Catherine A. Sarkisian ${ }^{5,6}$

\begin{abstract}
Background: Many older Hispanics/Latinos are physically inactive and suffer the harmful health consequences associated with prolonged periods of inactivity. Negative age attributions that equate getting older with "slowing down" reinforce this inactive behavior. We implemented a community-based exercise intervention among insufficiently active older Hispanics/Latinos with a randomized trial of an attribution-retraining program, ¡Caminemos! (Let's Walk!), and measured the effect of the program on walking behavior.
\end{abstract}

Methods: Five hundred and seventy-two older Hispanics/Latinos ( $\geq 60$ years) were enrolled in an exercise program that randomly assigned participants to the exercise class and one of two conditions: (a) treatment (attribution retraining to dispel the notion that physical activity inevitably ceases with age) or (b) control (generic health education). Data were collected at baseline and follow-up (1, 12, and 24 months). Physical activity was determined through pedometer data and the Yale Physical Activity Survey. We also measured the intervention effects on age-expectations, self-efficacy expectations, and outcome expectations for physical activity. Mixed-effects regression models were used to determine intervention effects on prospective measures of physical activity and intrapersonal expectations.

Results: The sample had a mean age of 73 years (SD $=6.8)$ and was $77 \%$ female, and $76 \%$ of the sample reported income $<\$ 20,000$. At baseline, control and treatment groups walked about 3000 steps/day. By 24 months, participants in both arms of the intervention maintained greater than 10,000 mean steps/day, but the difference between the groups was not statistically significant. In analyses adjusted for age, sex, education, income, health status, and acculturation, participants in both trial arms increased their mean numbers of steps at 12 and 24 months, with the treatment group showing a greater number of mean steps compared to the controls at 12 months.

Conclusions: In this group of physically inactive older Hispanics/Latinos, attribution retraining in combination with an exercise class was superior to the exercise class alone with regard to increasing walking behavior. This success was sustained at 12 months (the pre-defined primary study outcome) but not at 24 months. For older Hispanics/Latinos, enrollment in an attribution-retraining exercise program can improve an inactive lifestyle.

Trial registration: clinicaltrials.gov identifier: NCT00183014.

Keywords: Hispanic/Latino, Older adults, Physical activity, Intervention, Behavior change, Attribution retraining

\footnotetext{
* Correspondence: Impiedra@illinois.edu

'School of Social Work, University of Illinois at Urbana-Champaign, 1010 West

Nevada St, Urbana, IL 61801, USA

Full list of author information is available at the end of the article
}

(c) The Author(s). 2018 Open Access This article is distributed under the terms of the Creative Commons Attribution 4.0 International License (http://creativecommons.org/licenses/by/4.0/), which permits unrestricted use, distribution, and reproduction in any medium, provided you give appropriate credit to the original author(s) and the source, provide a link to the Creative Commons license, and indicate if changes were made. The Creative Commons Public Domain Dedication waiver (http://creativecommons.org/publicdomain/zero/1.0/) applies to the data made available in this article, unless otherwise stated. 


\section{Background}

In the United States, Healthy People 2020 sets forth 10-year national objectives for improving the health of Americans [1, 2]. Featured prominently in this report is a call for dramatically increasing physical activity, levels among older adults, including those with physical and cognitive limitations [1, 2]. Adults 65 years and older spend about $80 \%$ of their waking time (10-12 h per day) doing sedentary activities (sitting or reclining) [3-5]. Sitting or reclining requires minimal energy expenditure (1.0-1.5 basal metabolic rate) [6] and poses a significant health risk if daily exposure is prolonged [7-11]. Conversely, physical activity has emerged as an important determinant of functional independence, quality of life, and healthful longevity [12, 13]. Evidence shows that, among older adults, even small amounts of time one can replace sedentary behavior, such as watching TV or sitting in a car, with low, moderate or vigorous physical activity can improve physical function [14, 15]. Regular physical activity can forestall chronic diseases such as obesity [16, 17] and diabetes [18]. Thus, increasing physical activity among older adults is a public health priority [19].

Hispanic/Latino older adults, who make up about $8 \%$ of the older adult population in the United States and whose numbers are projected to grow to $20 \%$ over the next three decades [20-22], are disproportionately sedentary; rates of regular physical activity are reported to be as low as $10 \%$ [23] and substantially lower than for non-Hispanic whites [23-26]. Low levels of physical activity serve as an antecedent to multiple chronic diseases for which Hispanic/ Latino adults experience elevated risk and associated health disparities. For instance, Hispanic/Latino older adults disproportionately suffer from obesity [27, 28], diabetes [29], and cardiovascular disease [30, 31], contributing to a marked decline in quality of life [32, 33] and higher levels of functional impairments [32].

Pre-existing cultural expectations about older age may contribute to one becoming increasingly inactive with age and may compound the ill effects of other factors, such as low levels of acculturation and education and diminished social support [34, 35]. Some studies have noted that despite acknowledging the benefits of exercise, older Hispanic/Latino adults feel that such exertions are not appropriate, in part because of the perceived risk of injury $[36,37]$. Though most people lower their expectations for how healthy they will be as they age, Latinos have especially low age-expectations compared to non-Latino whites and African Americans [38]. These low age-expectations, in particular attributing being sedentary to "old age," are associated with low rates of physical activity and increased sedentary behavior, which may also contribute to evident health disparities [34, 36, 38-41].
Beliefs, behavior, and age attribution

To promote physical activity in older adults [42-45] most exercise programs combine multiple elements across theoretical models to inform behavior change [46-48]. Among these theoretical models, social cognitive theory has garnered much empirical support [49, 50]; whether application of attribution theory can be successfully used to change physical activity behavior in seniors has not been examined in a randomized trial to our knowledge [39, 40].

Social cognitive theory [43] posits that behavioral change occurs when goals are set based on: (a) self-efficacy expectations (the belief that one can accomplish a behavior) and (b) outcome expectancy (the belief that engaging in the behavior will deliver positive results). Evidence suggests that raising self-efficacy expectations through setting and achieving goals, behavior modeling, verbal persuasion, and reframing the interpretation of physiological states can encourage physical activity among older adults [49, 51]. In addition, outcome expectancy may be a powerful mediator of physical activity behavior change [52-54]. One study underscored the need for strategies to increase and maintain efficacy within interventions, especially for participants who start out with a lower sense of efficacy [53].

Scholars have long noted that the causal attributions one assigns to outcomes can influence behavioral motivation [39, 40, 55-59]. According to attribution theory, people are more likely to change their behavior when they believe that factors that contribute to outcomes are malleable and within their control [57-59]. According to attribution theory, such designations fall along three dimensions: (a) whether the person identifies an internal or external locus of causality; (b) the stability of the attribution (whether it is perceived as fixed or changeable); and (c) the extent to which the agent perceives that he or she can exert change over the attribution (controllability) [57, 59]. From this perspective, an attribution perceived as fixed and outside the person's control will demotivate behavioral change [57, 59]. For example, a woman diagnosed as hypertensive and who believes her condition is genetic (it "runs in the family") invokes a fixed (stable) and uncontrollable attribution. Such an ascription does not inspire behavioral change (to exercise, eat better, or self-monitor one's blood pressure). Instead, that person might opt merely to take a prescribed medication. However, if the same person reframes her condition as signaling a need for better self-care-an unfixed attribute well within her control-she might be more inclined to initiate health-promoting behavioral changes (diet, exercise, and self-monitoring) to forestall the progression of the condition. Attribution-retraining techniques encourage people to rethink their beliefs so that they come to see outcomes as changeable based on 
behaviors within their control. We hypothesized that such techniques may be especially promising for older adults who are likely to attribute physical inactivity and health deteriorations to normal "old age."

Thus, this study combines social cognition theory with attribution theory in an attribution-retraining curriculum to determine whether a random sample of older Hispanic/Latino adults exposed to the curriculum would experience an enhanced response to a modified version of a low-cost exercise program (EnhanceFitness ${ }^{\circ}$ ) when compared to those who received a health education curriculum (see Fig. 1). We hypothesized that exposure to the curriculum would promote higher levels of physical activity compared to those who received generic health education (at 1 month) and that this enhanced performance would be maintained over time (at 12 and 24 months). We also hypothesized that the intervention would have a similar influence on age-expectations, self-efficacy and outcome expectations for exercise among older adults.

\section{Methods/design}

Trial design

Figure 2 presents a consort diagram of the study design and timeframe. We enrolled 572 Hispanic/Latino older adults in an exercise program and applied a double-blind randomized controlled trial design with two arms: (a) those who received the attribution-retraining curriculum (treatment group) and (b) those who received general health education (control group). Previous studies detail the ${ }_{i}$ Caminemos! recruitment and study protocol [39, 60]. The trial was pre-registered at clinicaltrials.gov (identifier NCT00183014). The UCLA Office for Protection of Research Subjects approved the study protocol.

\section{Participant recruitment and enrollment}

Project staff recruited and enrolled participants between August 2005 and August 2007 from 27 community-based senior centers located throughout Los Angeles County that partner with the City and/or County of Los Angeles to provide senior services such as inexpensive mid-day meals, recreational activities, and assistance with social needs such as housing and transportation. Because of the heterogeneity of the Latino population in greater Los Angeles, we decided not to randomize by site; the senior centers differed greatly from each other in terms of site infrastructure characteristics and participant socioeconomic status, activity level, and functional status. In addition, randomization by sites would have been very unattractive to our community partners (those assigned to a control group would not receive the full intervention) and would require a much larger sample size. Thus, randomization occurred at the level of the individual.

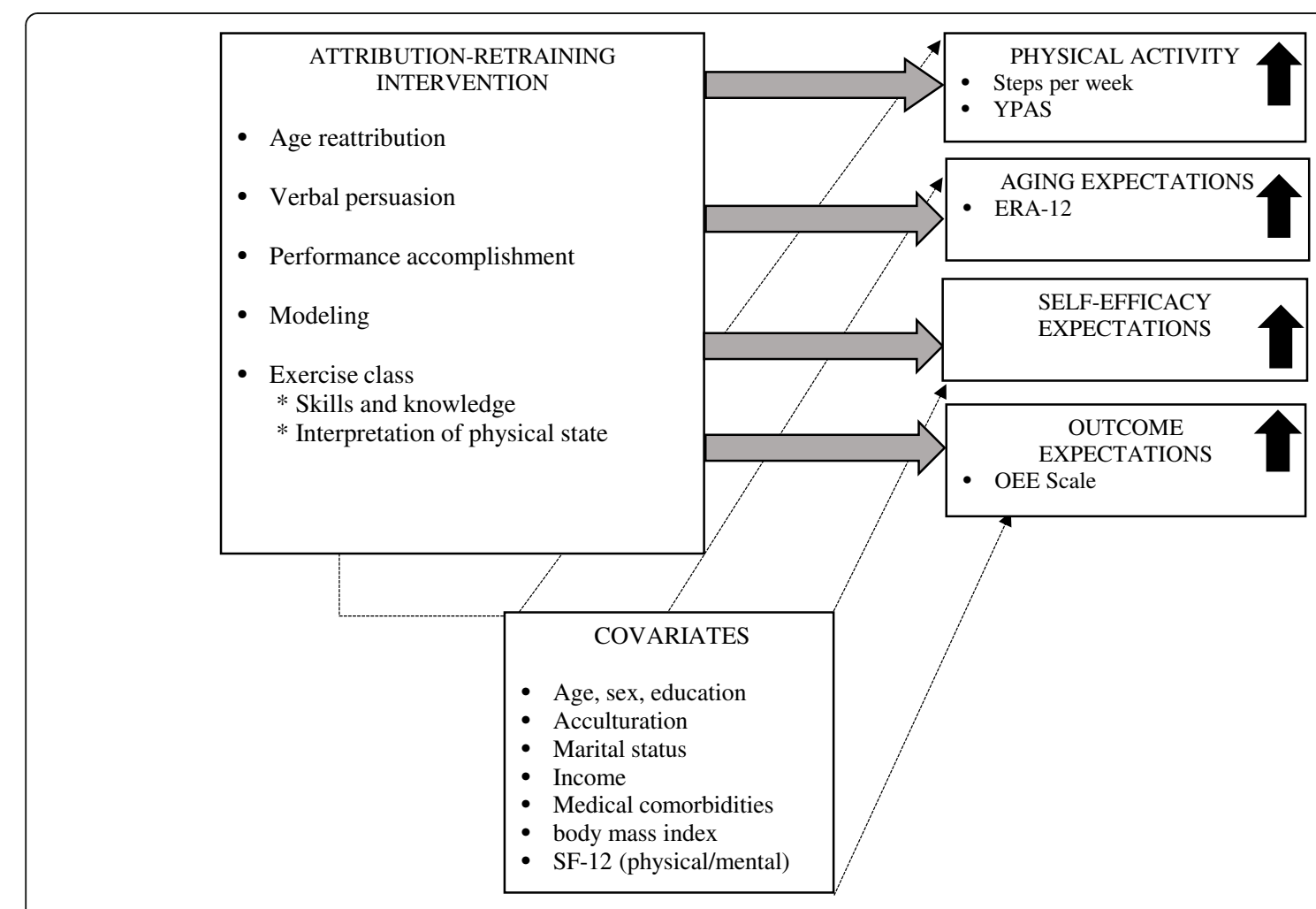

Fig. 1 Conceptual framework 


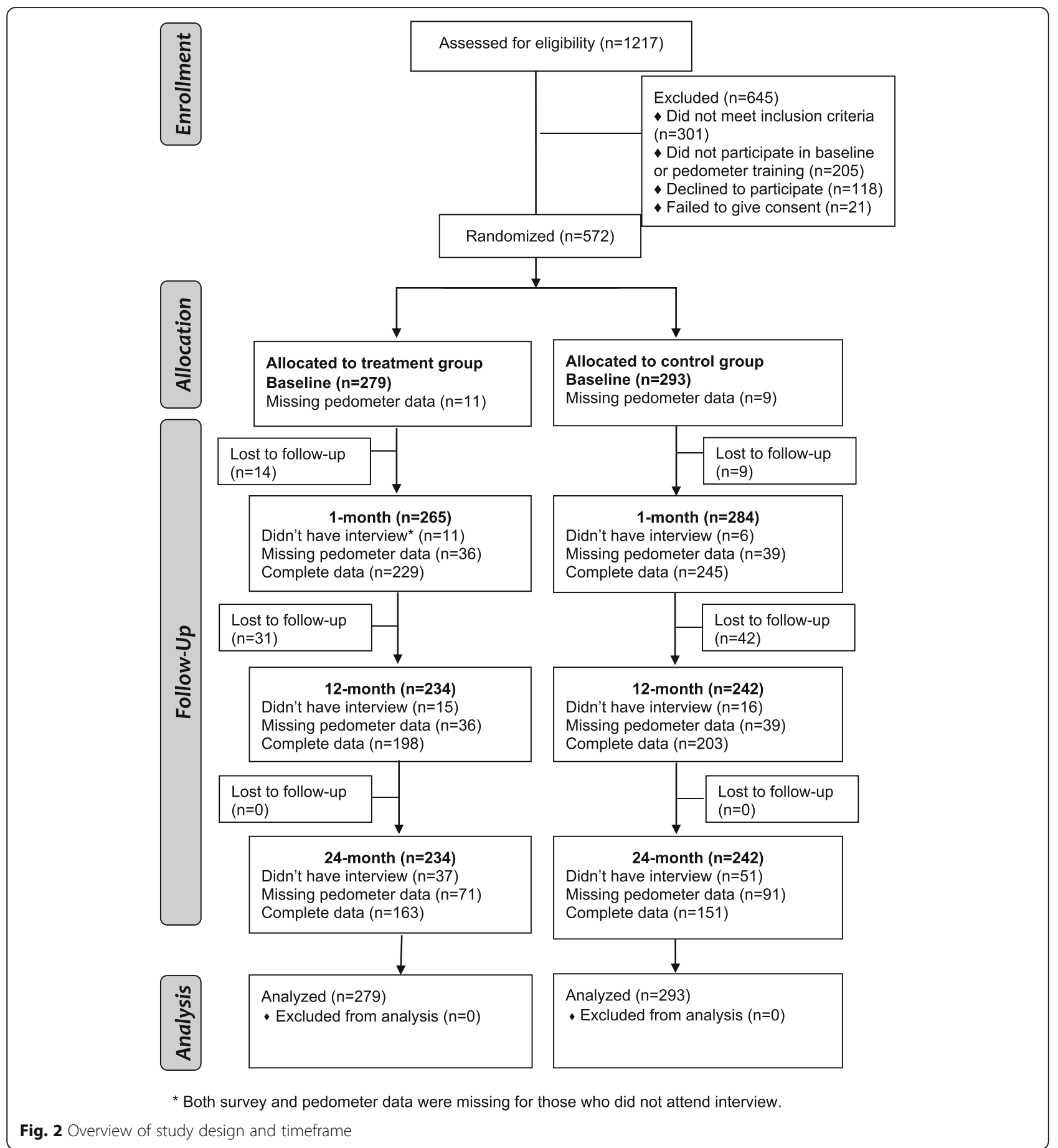

We used a two-step protocol that included a face-to-face screening with application of exclusion criteria (Step 1). To be eligible, potential participants had to: (a) be 60 years of age or older, (b) self-identify as Latino, (c) be verbally fluent in English or Spanish, (d) be cognitively intact as determined by a six-item cognitive screener [61], (e) be able to walk (the use of assistive devices such as canes or walkers was not an exclusion criterion); (f) be physically inactive, which was defined as engaging in less than 20 min of exercise at least three times per week; and (g) be available and able to attend weekly exercise and education classes held at the senior center. We set our exclusion criteria of $20 \mathrm{~min} 3 \times /$ week, which is below the recommended levels of $150 \mathrm{~min}$ of moderate intensity activity over the week, because our focus was on those seniors most in need of starting a 
walking program. Potential participants who were eligible based on the Step 1 screening protocol provided the name of a primary care physician who had seen them in the past year; this physician was sent a fax describing the study and asked to send a response fax if the patient had any medical contraindication to participating in a walking program. Potential participants who wanted to enroll but had not seen a physician were offered appointments at local doctors' offices that accepted sliding scale payments. We excluded spouses or others living with anyone who was also enrolled (due to increased risk of contamination) but allowed spouses/ housemates to attend the classes without enrolling (and we did not collect any data on them).

After 1 week had passed without receipt of a fax from the physician indicating a medical contraindication, potential participants were invited to a one-on-one orientation session at the senior center, during which trained staff explained the study and obtained written informed consent to participate. Participants were given a pedometer, trained to use it, and told to return a week later, at which point trained bilingual staff collected baseline data. Of 1217 potential participants screened, 645 $(53.0 \%)$ were excluded for the following reasons: (a) did not meet the study criteria $(n=301)$, the most common reason being scheduling conflicts due to childcare responsibilities; (b) did not participate in baseline or pedometer training $(n=205)$; (c) declined to participate $(n=118)$; or (d) failed to complete informed consent $(n=21)$ (see Fig. 2).

\section{Randomization}

Randomization occurred once the participants had scheduled their appointment to provide baseline data. We followed an allocation sequence that randomized at the level of the individual (instead of senior centers). Participants were randomized using a random number sequence generator using SAS software (SAS Institute, Cary, NC). Our project staff generated the allocation and a staff-member who was not involved in data collection notified participants of their assignment to the "red" (control) or "orange" (treatment) group after all baseline data collection was completed. Couples were randomized as a unit (only one member of the couple was allowed to enroll in the study, but the other member of the couple could participate in all activities other than data collection). Occasionally a potential participant would be part of our computer randomization but did not complete baseline data collection, leading to a non-equal number of participants for each group.

\section{Blinding}

The labels "red group" and "orange group" were used to "blind" participants to the study design and to the primary hypotheses of the study. All participants and staff involved in data collection were kept blind to which arm of the study participants were allocated. Because it was likely that participants from both arms of the study would know each other and might talk to one another about what they had learned, additional precautions were taken to minimize contamination-biasing results toward the null hypothesis. These safeguards included: (a) keeping all instructors uninformed of the study's hypotheses, (b) not permitting the exercise instructors to see the attribution-training curriculum or observe a group discussion, and (c) once randomized, keeping participants in both arms of the study separate throughout the intervention and data collection. We held separate exercise classes for orange and red group participants. Participants in both arms of the study were exposed to the same amount of staff contact $(8 \mathrm{~h}$ over 4 weeks for the first month, $4 \mathrm{~h}$ per week for the next 11 months, then once every 2 months for the final 12 months of the study).

\section{Intervention procedures}

After eligible participants were enrolled, provided baseline data, and were randomized into the "red" or "orange" group, they participated for 4 consecutive weeks in a weekly 1-h group discussion session of 8-10 participants led by a bilingual health educator who followed the curriculum for either the attribution retraining (treatment group) or the generic health education (control group). The generic health education group received a series of didactic PowerPoint presentations created by project staff on topics related to senior wellness (e.g. disaster preparedness). In about half the sites (14), the group discussions and the exercise classes were held on the same day; at other sites, they were hosted separately. The scheduling was left was up to the discretion of the sites.

Exercise program. In addition to the group discussion session (described in detail below), participants in both arms of the study separately received a 1-h exercise class (weekly for 4 weeks), which targeted muscle strength, endurance, balance, and flexibility. The exercise classes were a modified version of the EnhanceFitness ${ }^{\bullet}$ Program (previously called the Lifetime Fitness Program $\odot$ ) administered by Senior Services (Seattle), designed to be safe for seniors and offering both sitting (chair) and standing options for each exercise [62]. All EnhanceFitness $^{\circ}$ sessions are designed to be safe for seniors with a wide range of physical capabilities.

\section{Intervention (treatment) description}

A multidisciplinary team of investigators combined attribution theory with social cognitive theory to develop a standardized curriculum to be delivered by trained 
health facilitators that underscored the idea that becoming physically inactive should not be an expected part of aging. In one early session, participants were tasked with stating the reasons for being insufficiently active, and then taught to categorize the reasons as either immutable (e.g. being old, having a medical condition) or mutable (e.g. being lazy, not having a partner to exercise with). The trained facilitator taught participants to change their attributions from those that are immutable (in particular, old age) to those that are mutable, and then to problem solve together as a group how to address the mutable reasons for being insufficiently active. Participants established action plans to increase physical activity and made a "promise" to do a specific action before the next meeting (e.g. walk for 15 min every other day). All treatment group participants were encouraged to write down how much walking/exercise they did each day and comment at the beginning of each session on how well they kept their "promise." They also recorded any obstacles they encountered and the extent to which they were able to overcome the obstacles. Based on data showing that behavioral changes are more likely to be sustained if people are given a chance to ponder how their beliefs have changed [63,64], at the final core session, facilitators asked each participant to reflect and comment on attitudinal alterations that occurred over the four sessions.

\section{Reinforcement schedule}

After the 4-week "core intervention" period, all participants in both arms of the study received follow-up (reinforcement) sessions, including both 1-h exercise classes and either the attribution retraining or health education classes. These reinforcement classes met monthly for 11 months after the "core intervention" period and every 2 months for an additional 12 months (total intervention duration $=24$ months). Both the treatment and the control groups were exposed to equal amounts of contact time with study staff. During the reinforcement sessions, the treatment group received verbal support for the attribution-retraining concepts they had learned during the 1-month "core" intervention, while the control group received new health education classes.

\section{Health educator training and fidelity}

Bilingual health educators were recruited from the general community via formal job postings as well as word of mouth. Study personnel trained all potential health educators as group leaders over a 2-day period following a standard curriculum that included general group facilitation techniques as well as step-by-step instructions for each of the four core sessions as well as the reinforcement sessions. Each potential health educator led a "mock" session prior to the start of the study; one potential health educator who did not follow the curriculum correctly was not allowed to lead groups. To measure fidelity to the curriculum, all sessions were audiotaped and reviewed by study personnel to assure that approximately three key points for each session were emphasized; feedback to group leaders was provided as needed.

\section{Fotonovela}

Halfway through the intervention, we distributed a fotonovela (a photo-dramatized short story) to the treatment group that emphasized the concept that being physically inactive should not be an expected part of normal aging. In the fotonovela, the protagonist, a senior Hispanic/Latina woman, initially states that she is "too old" to exercise but then successfully embarks on walking for regular exercise. She concludes, "Even though I am not young, I realize now that I can control my health and feel better by walking." We modified the group leader curriculum to include passing out and discussing the fotonovela.

\section{Attrition and attendance}

We anticipated attrition due to death, illness, or lack of interest. We did not contact those who wished to withdraw formally from the trial. However, participants who stopped attending the program were encouraged to continue by telephone and through in-person meetings at the senior centers. When someone missed a discussion, exercise, and/or data collection, we attempted to reengage the person and obtain data. In such instances, we followed a multifaceted, IRB-approved protocol that guided outreach efforts. Overall, attendance rates were $80 \%$ for both arms of the intervention. Each group attended $80 \%$ of the group discussions and the exercise classes.

\section{Data collection/outcome measures}

Data collection included pedometer readings, an in-person interview to gather closed-ended survey items, a brief physical exam, and a series of performance measures [65-67]. After baseline, subsequent data collections were conducted at 1,12 , and 24 months, which included completing questionnaires and submitting pedometer recordings. Such data were collected from 474, 401, and 314 participants, respectively. After each data collection session a $\$ 25$ honorarium was provided.

\section{Physical activity}

Objective and self-reported measures were used to evaluate physical activity. As an objective measure, the Digiwalker pedometer (Yamax DW-500, New Lifestyles, Inc., Kansas City, MO) was used to calculate the average 
number of steps taken within a 1-week timeframe. It measures vertical accelerations and, when worn over the hip at waist level, accurately records the number of steps taken within a 3\% margin of error compared to direct observation and is substantially better than self-reporting $[39,68-70]$. During the weeks when the numbers of steps were recorded, each participant met with project staff at the beginning of the week. Project staff used a standardized script to teach participants how to properly wear and use the pedometer without looking at the step counts; the pedometer was intended as a data collection tool, not as a motivator in itself. Staff reset the pedometer to zero and taped the display window with a label that indicated the meeting date. The participants were instructed not to open their pedometers for the entire week and to return to the senior center at the same time the following week. During that time, the participants were asked to wear the pedometers at all times (7 days), excluding those times when they slept, swam, or bathed. For each participant in the treatment and control groups, the recorded number of steps collected accumulatively over the previous 7 days was downloaded to a computer at a single point during baseline and then at 1, 12. and 24 months. If there were days with no recorded steps, it was assumed that the pedometer was not worn that day, and that information was omitted when calculating the average number of steps over the previous 7 non-zero days with a minimum of 4 days. If there were no 4 days with non-zero steps, the pedometer data were coded as missing.

The Yale Physical Activity Survey (YPAS) [71] was used to measure self-reported perceptions of physical activity in older adults across a wide range of undertakings. The YPAS has two sections that generate three scores. First, participants are asked to assess the total time spent on a list of 25 activities in a typical week during the previous month. Second, participants report the frequency and duration of physical activity in five distinct dimensions: vigorous activity, leisure walking, moving, standing, and sitting. The first section is used to calculate a total time summary index (total time spent doing any of the listed activities) and an energy expenditure summary index (total time spent doing each activity multiplied by a kcal intensity code and summed over all activities). The second section is used to obtain an estimate for the activity dimensions summary score, calculated by multiplying the time spent in each dimension by a weight that ranges from 5 for vigorous activity to 1 for sitting and then adding the weighted totals across all five activity dimensions. The Spanish version of the YPAS has been found to be a valid and reliable measure of activity for older adults [72].

\section{Expectations regarding aging (ERA-12)}

The ERA-12, a modified version of the ERA-38 [73], measures age-expectations in older adults with demonstrated reliability and validity [74]. Evidence suggests that older adults' perceptions of aging influence their further health outcomes [75-77]. The survey consists of 12 questions, representing three domains of expectations (four items each): general health, mental health, and cognitive function. A total score for aging expectations is obtained by combining all 12 items [74]. Sub-scale and total scores on the ERA-12 range from 0 to 100, with higher scores indicating higher aging expectations for physical, cognitive, and mental functioning; lower scores indicate lower expectations associated with physical, cognitive, and mental decline [74]. Internal consistency reliability estimates for all scales were reported to exceed 0.74 [74].

\section{Lorig self-efficacy for exercise scale (modified)}

This instrument consists of four items and uses a Likert scale (1, not at all confident, to 10 , totally confident) to measure a person's confidence in his or her ability to regularly engage in moderately intensive exercise three to four times per week in the future (1-, 2-, 4-, and 8 -weeks) without exacerbating preexisting symptoms. This scale has been translated into Spanish version and found to be a valid and reliable measure of self-efficacy for exercise in older adults $(\alpha=.92)$ [78].

\section{Outcome expectation for exercise scale (OEE)}

The OEE is a nine-item scale that measures the outcome expectations for exercise among older adults [79]. Outcome expectations are the beliefs that carrying out a specific behavior-in this case, exercise-will lead to a desirable outcome (e.g. losing weight, reduced glucose levels) or perceived benefits (e.g. feeling energetic or relaxed). Such expectations have been found to be positively associated with exercise behavior [80]. OEE scores range from 1 to 5 , with 1 suggestive of low outcome expectations for exercise, and 5 suggestive of strong outcome expectations for exercise. The OEE scale has adequate internal consistency $(\alpha=.89)$ and existing evidence show support for its reliability and validity [79]. The evidence of validity indicates that those who exercised regularly had higher OEE scores than those who did not $(F=31.3, p<.05)$ [79]. Moreover, a statistically significant relationship was found between outcome expectations and self-efficacy expectations $(r=.66)$ [79].

\section{Covariates}

Sociodemographic measures, health status, and level of acculturation were included as potential confounders. The sociodemographic factors assessed were age, sex, education, marital status, and income. The health status measures included body mass index (BMI), medical comorbidities, and physical and mental quality of life. 


\section{Sociodemographic measures}

Demographic variables included age in years and sex (male [reference group], female). Categorical values were created when capturing the covariates of education (no schooling completed [reference group], seighth grade, or some high school and above), income level $(<\mathrm{US} \$ 20,000$ [reference group], US $\$ 20,000$ or more, missing income), and marital status (never married [reference group], married, separated/divorced, or widowed).

\section{Health status measures}

BMI was calculated as weight $(\mathrm{kg}) /$ height $(\mathrm{m})^{2}$ and classified as underweight $(<18.5)$, normal $(18.5$ to $<25)$, overweight (25 to $<30$ ), or obese (30 or higher). Because there were relatively few underweight participants $(n=$ 4 ), we combined this group with those of normal weight in the analyses.

Because medical comorbidities affect health outcomes, participants indicated the presence of 16 disorders using a self-administered questionnaire modeled after the Charlson Comorbidity Index [81]. These included any of the following conditions: (a) high blood pressure; (b) heart attack; (c) congestive heart failure; (d) stroke; (e) diabetes; (f) arthritis; (g) hip fracture; (h) fracture of wrist, arm, or spine; (i) lung disease; (j) liver disease; (k) cancer; (l) Parkinson's disease; (m) coronary artery bypass surgery; (n) Alzheimer's disease or dementia; (o) depression; and (p) anxiety. Any indicated condition received a score of 1 and was added together with nonexistent conditions, which were marked as 0 . The total score was treated as a continuous measure, with scores ranging from 0 to 16 .

The 12-Item Short-Form Health Survey (SF-12) provides a generic measure of health status by examining eight health concepts: physical functioning, role limitations due to health problems, bodily pain, general health, vitality, social functioning, role limitations due to emotional problems, and mental health [82]. The instrument generates component summaries for physical and mental health through a principal components analysis. Although SF-12 yields norm-based scores for two broad aspects of health-physical and mental-all items are used to score both summary measures, with a higher score indicative of a better health state [83].

\section{Short acculturation scale for Hispanics (SASH)}

SASH identifies low and high levels of acculturation, which commonly refers to the process of cultural and psychological change that occurs through intercultural contact $[84,85]$. SASH uses a 12 -item survey to measure language use, media, and ethnic social relations on a four-point scale [86]. Responses are averaged across the items, and scores range from 1 to 4, with higher scores representing greater acculturation. An overall average score of 2.99 differentiates less acculturated respondents $(\leq 2.99)$ from the more acculturated (>2.99).

\section{Data analysis}

To assess the success of the randomization, we calculated descriptive statistics for sociodemographic factors, health status, acculturation levels, and pedometer data at baseline for those who were in the treatment and control groups. Results for continuous variables were generated as mean $\pm \mathrm{SD}$, and, for the categorical variables; results are given as count and percentage in each category. Comparisons between treatment and control groups were performed with $\mathrm{t}$-test (continuous variables) or chi-square test (categorical variables). All analyses were performed using STATA SE 14.2.

Differences in retention between the treatment and control arms were tested using log-rank test. Two sample t-tests were used to compare the continuous variables over time between the treatment and control arms.

To test the primary study hypothesis concerning the effect of the behavioral intervention on the treatment compared to the control groups over time, we constructed a repeated mixed-effects linear regression $[87,88]$ to analyze longitudinal changes in the outcome variables as a result of the exercise class and the attribution-retraining component. Repeated mixed-effects regressions allow for an unequal number of observations across individuals, which is an advantage over generalized linear models. Repeated mixed-effects regression models also handle nested data inherent to repeated observations within individuals. All outcome measures were treated as continuous variables. The regression models included treatment group, time in years, and the interaction of group and time, as well as terms for baseline covariates-sociodemographic factors, health status, and acculturation levels. Random effects for the intercept were included to allow individuals to vary in the initial baseline values. In order to facilitate the interpretation of regression results related to the pedometer data, particularly the interaction effects, we examined the linear predictions obtained with the "margins" command and the contrasts involving factor variables and their interactions using the "contrast" command.

\section{Results}

\section{Baseline characteristics}

Nearly $80 \%$ of the participants were born outside the United States, and nearly two-thirds of sample participants completed the survey in Spanish. Table 1 displays the baseline distributions of sociodemographic factors, health status and acculturation levels for whole sample and by each arm of the intervention. As a group, the participants ranged in age from 60 to 93, with a mean age of $73.1(\mathrm{SD}=6.8)$ and a 
Table 1 Descriptive statistics of individual-level covariates in the ¡Caminemos! study

\begin{tabular}{|c|c|c|c|}
\hline \multirow[t]{3}{*}{ Variables } & \multirow{3}{*}{$\begin{array}{l}\text { All } \\
\overline{N(\%)^{a}}\end{array}$} & \multicolumn{2}{|l|}{ Group } \\
\hline & & \multirow{2}{*}{$\begin{array}{l}\text { Control } \\
\mathrm{N}(\%)^{\mathrm{a}}\end{array}$} & \multirow{2}{*}{$\begin{array}{l}\text { Treatment } \\
\mathrm{N}(\%)^{*}\end{array}$} \\
\hline & & & \\
\hline Mean age (SD) & $73.1(6.8)$ & $73.2(6.8)$ & $73.1(6.7)$ \\
\hline \multicolumn{4}{|l|}{$\operatorname{Sex}(n=572)$} \\
\hline Male & $131(22.9)$ & $58(19.8)$ & $73(26.2)$ \\
\hline Female & $441(77.1)$ & $235(80.2)$ & $206(73.8)$ \\
\hline \multicolumn{4}{|l|}{ Education $(n=572)$} \\
\hline No schooling completed & $83(14.5)$ & $49(16.7)$ & $34(12.2)$ \\
\hline$\leq 8$ th grade & $256(44.8)$ & $132(45.1)$ & $124(44.4)$ \\
\hline Some high school or more/other & $233(40.7)$ & $112(38.2)$ & $121(43.4)$ \\
\hline \multicolumn{4}{|l|}{ Marital status $(n=570)$} \\
\hline Never married & $72(12.6)$ & $41(14.0)$ & $31(11.2)$ \\
\hline Married & $164(28.8)$ & $77(26.4)$ & $87(31.3)$ \\
\hline Separated/divorced & $128(22.5)$ & $61(20.9)$ & $67(24.1)$ \\
\hline Widowed & $206(36.1)$ & $113(38.7)$ & $93(33.5)$ \\
\hline \multicolumn{4}{|l|}{ Income $(n=572)$} \\
\hline$<\$ 20,000$ & $432(75.5)$ & $221(75.4)$ & $211(75.6)$ \\
\hline$\$ 20,000$ and above & $90(15.7)$ & $46(15.7)$ & $44(15.8)$ \\
\hline Missing & $50(8.4)$ & $26(8.9)$ & $24(8.6)$ \\
\hline Mean medical comorbidities (SD) $(n=572)$ & $2.6(1.5)$ & $2.7(1.8)$ & $2.6(1.5)$ \\
\hline \multicolumn{4}{|l|}{ BMl categories $(n=569)$} \\
\hline Underweight and normal & $93(16.3)$ & $47(16.2)$ & $46(16.5)$ \\
\hline Overweight & $213(37.4)$ & $105(36.1)$ & $108(38.8)$ \\
\hline Obese & $263(46.2)$ & $139(47.8)$ & $124(44.6)$ \\
\hline Mean SF-12: Norm-based standardization of scale scores (Physical) (SD) $(n=572)$ & $41.5(9.6)$ & $41.3(10.3)$ & $41.8(9.6)$ \\
\hline Mean SF-12: Norm-based standardization of scale scores (Mental) (SD) $(n=572)$ & $50.3(11.3)$ & $49.9(11.6)$ & $50.7(11.1)$ \\
\hline Mean level of acculturation (SD) $(n=572)$ & $2.1(1.3)$ & $2.0(1.3)$ & $2.2(1.3)$ \\
\hline
\end{tabular}

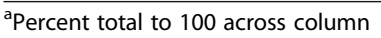

majority were female (77.1\%). More than half the sample had an 8th grade education or less. Only $12.6 \%$ had never married. They rest were married (28.8\%.), widowed $(36.1 \%)$ or separated/divorced $(22.5 \%)$. The majority (75.5\%) earned less than $\$ 20,000$ per year. On average, the participants had 2.6 medical comorbidities and $83.6 \%$ had a BMI indicative of being overweight or obese. The median SF-12 scores were 41.5 and 50.3, for physical and mental health, respectively. Levels of acculturation were relatively low with an average mean score of 2.1 points across participants. In the distribution of sociodemographic, health-status and acculturation levels measured at baseline, we found no statistical significant differences between the control and treatment groups.

\section{Retention and Fidelity}

The results for the study retention showed no statistically significant differences as tested by $\log \operatorname{rank}\left(\mathrm{x}^{2}=\right.$
1.89 , d.f $=1, p=0.17$ ) by group assignment (Fig. 3). The percentage of participants in the treatment group who completed the 2-year study period $(84 \%, N=234$ out of $279)$ was similar to that in the control group $(83 \%, N=$ 242 out of 293). We also found no differences in the retention related to the pedometer data and survey data (Fig. 3).

In addition, research personnel completed fidelity assessments by reviewing audiotapes for $90 \%$ of the sessions. Our assessments indicated that the group leaders successfully covered $80 \%$ of the key content in the curriculum.

\section{Changes over time in the outcome measures}

Tables 2, 3, 4 and 5 shows the estimates for the treatment and control groups for the outcome measures throughout the study period. 

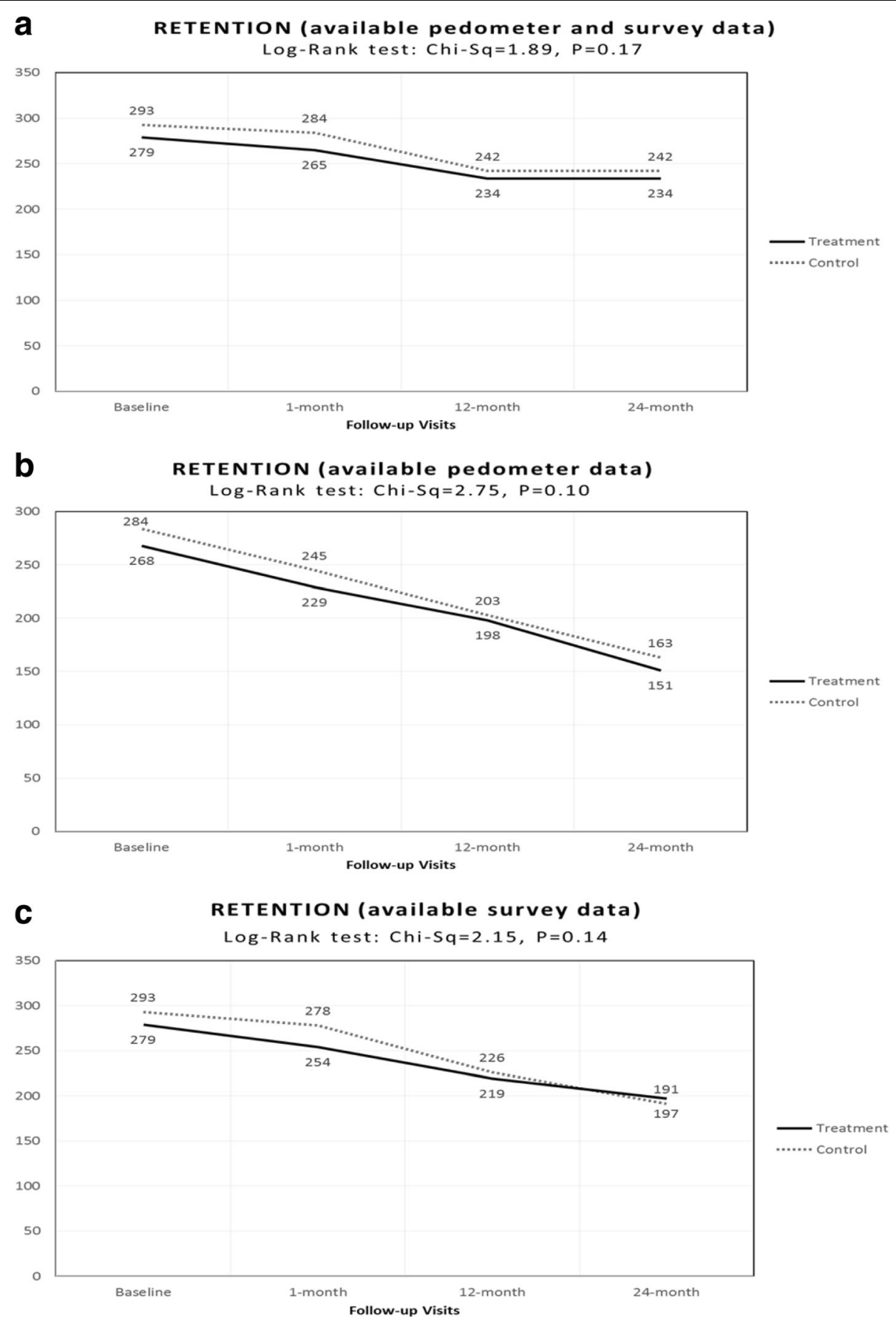

Fig. 3 Retention in the ¡Caminemos! Study. a RETENTION (available pedometer and survey data). b RETENTION (available pedometer data). c RETENTION (available survey data)

\section{Pedometer data}

Figure 4 displays the longitudinal changes in steps between the intervention and control groups. At baseline, the 7-day daily average for participants in both arms of the intervention numbered below 3200 steps, with no statistical difference between the two groups. One month later, the treatment group walked significantly more steps than the control group (3515.8 vs. 2671.3) $(p<.0001)$. At 12 months, participants in both arms of the intervention more than doubled their 7-day averages. The treatment group continued to outpace the control group (9365.4 vs. 8166.5) $(p<.05)$. By 24 months, participants in both arms of the intervention showed a 7-day average of more than 10,000 steps. Although the 
Table 2 Descriptive statistics for the outcome measures at baseline and at 1, 12, and 24 months for treatment and control groups: Baseline

\begin{tabular}{|c|c|c|c|c|c|c|c|}
\hline \multirow[t]{2}{*}{ Outcomes } & \multicolumn{2}{|l|}{ Control } & \multicolumn{2}{|c|}{ Treatment } & \multicolumn{2}{|c|}{ Difference between two groups } & \multirow[t]{2}{*}{$p$} \\
\hline & Mean & $95 \% \mathrm{Cl}$ & Mean & $95 \% \mathrm{Cl}$ & Mean & $95 \% \mathrm{Cl}$ & \\
\hline Pedometer & 2991.8 & $(2766.3,3217.2)$ & 3158.5 & $(2915.1,3402.0)$ & -166.7 & $(-497.4,164.0)$ & 0.3224 \\
\hline YPAS -Total time & 10.6 & $(9.8,11.5)$ & 11.3 & $(10.4,12.2)$ & -0.7 & $(-1.9,0.5)$ & 0.2502 \\
\hline YPAS - Energy expenditure & 2328.3 & $(2116.1,2540.5)$ & 2533.9 & $(2281.8,2786.1)$ & -205.6 & $(-533.3,122.1)$ & 0.2183 \\
\hline YPAS -Activity dimensions & 35.1 & $(32.6,37.6)$ & 38.3 & $(35.5,41.0)$ & -3.2 & $(-6.8,0.5)$ & 0.0898 \\
\hline ERA - Total score & 35.3 & $(33.2,37.4)$ & 34.8 & $(32.5,37.1)$ & 0.5 & $(-2.6,3.6)$ & 0.7524 \\
\hline ERA - Physical health scale & 30.3 & $(27.8,32.7)$ & 29.8 & $(27.3,32.3)$ & 0.5 & $(-3.0,4.0)$ & 0.7868 \\
\hline ERA - Mental health scale & 45.6 & $(42.6,48.5)$ & 43.8 & $(40.7,46.9)$ & 1.7 & $(-2.5,6.0)$ & 0.4242 \\
\hline ERA - Cognitive function scale & 30.0 & $(27.5,32.6)$ & 30.7 & $(28.0,33.4)$ & -0.7 & $(-4.4,3.0)$ & 0.7088 \\
\hline Exercise self-efficacy & 8.1 & $(7.9,8.3)$ & 8.0 & $(7.8,8.3)$ & 0.1 & $(-0.3,0.4)$ & 0.7126 \\
\hline Outcome expectation for exercise & 4.5 & $(4.4,4.5)$ & 4.4 & $(4.4,4.5)$ & 0.0 & $(-0.1,0.1)$ & 0.3985 \\
\hline
\end{tabular}

treatment group averaged more steps compared to the control group (11,604 vs. $10,593.9$ steps), this was not a statistically significant difference $(p=0.096)$.

\section{Survey data}

With one exception, no differences were found between the treatment and control groups for each of the survey data measures (YPAS, ERA-12, exercise self-efficacy, and outcome expectation for exercise) throughout the study. At the 12-month follow-up, the treatment group displayed greater mental health expectations regarding aging than the control group (55.7 vs. 46.9, $p<0.01$ ). Compared to their baseline averages, participants in both arms of the study showed an increase in their average scores for the YPAS, the ERA-12, exercise self-efficacy, and outcome expectations.

\section{Adjusted models}

Table 6 shows the estimated effects from the mixed-effects linear models (coefficients and 95\% CIs) of treatment versus control on outcome measures at baseline and at 1, 12, and 24 months. In analyses adjusted for sociodemographic factors, health status, and acculturation levels, participants in both trial arms displayed greater numbers of steps at the 12-month and 24-month follow-ups when compared to original baseline scores (Tables 6 and 7). Participants in the treatment group showed greater improvement in pedometer steps at 12 months than those assigned to the control group, (6190, 95\% CI 5531-6850 and 5099, 95\% CI 4450-5749) (Table 7). At 24 months, the difference across trial arms was not significant. Nonetheless, the control group reached 10,564 steps on average (95\% CI 6810-8201), and the treatment group averaged 11,458 steps (95\% CI

Table 3 Descriptive statistics for the outcome measures at baseline and at 1, 12, and 24 months for treatment and control groups: 1-month follow-up

\begin{tabular}{|c|c|c|c|c|c|c|c|}
\hline \multirow[t]{2}{*}{ Outcomes } & \multicolumn{2}{|l|}{ Control } & \multicolumn{2}{|c|}{ Treatment } & \multicolumn{2}{|c|}{ Difference between two groups } & \multirow[t]{2}{*}{$p$} \\
\hline & Mean & $95 \% \mathrm{Cl}$ & Mean & $95 \% \mathrm{Cl}$ & Mean & $95 \% \mathrm{Cl}$ & \\
\hline Pedometer & 2671.3 & $(2416.5,2926.1)$ & 3515.8 & $(3197.2,3834.3)$ & -844.5 & $(-1248.6,-440.3)$ & $<0.0001$ \\
\hline YPAS -Total time & 10.4 & $(9.6,11.1)$ & 11.0 & $(10.2,11.7)$ & -0.6 & $(-1.7,0.5)$ & 0.3004 \\
\hline YPAS - Energy expenditure & 2279.2 & $(2096.5,2461.8)$ & 2419.6 & $(2219.0,2620.2)$ & -140.4 & $(-410.4,129.6)$ & 0.3075 \\
\hline YPAS -Activity dimensions & 40.9 & $(38.3,43.6)$ & 42.9 & $(40.0,45.8)$ & -2.0 & $(-5.8,1.9)$ & 0.3212 \\
\hline ERA - Total score & 38.6 & $(36.3,41.0)$ & 40.0 & $(37.5,42.4)$ & -1.3 & $(-4.7,2.1)$ & 0.4405 \\
\hline ERA - Physical health scale & 34.4 & $(31.8,37.0)$ & 35.6 & $(32.9,38.4)$ & -1.2 & $(-5.0,2.6)$ & 0.5271 \\
\hline ERA - Mental health scale & 48.9 & $(45.6,52.1)$ & 50.8 & $(47.5,54.1)$ & -2.0 & $(-6.6,2.6)$ & 0.3999 \\
\hline ERA - Cognitive function scale & 32.6 & $(29.9,35.4)$ & 33.4 & $(30.8,36.1)$ & -0.8 & $(-4.6,3.0)$ & 0.6769 \\
\hline Exercise self-efficacy & 8.3 & $(8.1,8.6)$ & 8.4 & $(8.1,8.7)$ & -0.1 & $(-0.5,0.3)$ & 0.6086 \\
\hline Outcome expectation for exercise & 4.7 & $(4.6,4.7)$ & 4.6 & $(4.6,4.7)$ & 0.0 & $(0.0,0.1)$ & 0.3786 \\
\hline
\end{tabular}


Table 4 Descriptive statistics for the outcome measures at baseline and at 1, 12, and 24 months for treatment and control groups: 12-month follow-up

\begin{tabular}{|c|c|c|c|c|c|c|c|}
\hline \multirow[t]{2}{*}{ Outcomes } & \multicolumn{2}{|l|}{ Control } & \multicolumn{2}{|c|}{ Treatment } & \multicolumn{2}{|c|}{ Difference between two groups } & \multirow[t]{2}{*}{$p$} \\
\hline & Mean & $95 \% \mathrm{Cl}$ & Mean & $95 \% \mathrm{Cl}$ & Mean & $95 \% \mathrm{Cl}$ & \\
\hline Pedometer & 8166.5 & $(7418.9,8914.1)$ & 9365.4 & $(8627.9,10,102.9)$ & -1198.9 & $(-2246.2,-151.6)$ & 0.0250 \\
\hline YPAS -Total time & 10.6 & $(9.8,11.4)$ & 10.7 & $(9.9,11.5)$ & -0.1 & $(-1.3,1.0)$ & 0.7951 \\
\hline YPAS - Energy expenditure & 2296.8 & $(2106.2,2487.4)$ & 2333.8 & $(2139.4,2528.2)$ & -37.1 & $(-308.6,234.4)$ & 0.7885 \\
\hline YPAS -Activity dimensions & 38.1 & $(35.3,40.9)$ & 41.6 & $(38.6,44.6)$ & -3.5 & $(-7.6,0.6)$ & 0.0971 \\
\hline ERA - Total score & 37.7 & $(34.6,40.7)$ & 41.9 & $(38.9,44.9)$ & -4.2 & $(-8.5,0.1)$ & 0.0528 \\
\hline ERA - Physical health scale & 33.5 & $(30.2,36.7)$ & 35.4 & $(32.0,38.8)$ & -2.0 & $(-6.7,2.7)$ & 0.4107 \\
\hline ERA - Mental health scale & 46.9 & $(42.9,51.0)$ & 55.7 & $(51.9,59.6)$ & -8.8 & $(-14.4,-3.3)$ & 0.0020 \\
\hline ERA - Cognitive function scale & 32.6 & $(29.2,36.0)$ & 34.5 & $(31.2,37.8)$ & -1.9 & $(-6.6,2.8)$ & 0.4176 \\
\hline Exercise self-efficacy & 8.4 & $(8.1,8.7)$ & 8.3 & $(8.0,8.6)$ & 0.1 & $(-0.3,0.5)$ & 0.6645 \\
\hline Outcome expectation for exercise & 4.7 & $(4.6,4.7)$ & 4.7 & $(4.6,4.7)$ & 0.0 & $(-0.1,0.1)$ & 0.9178 \\
\hline
\end{tabular}

7639-9011) at the 24-month follow-up (Table 7). There were no differences between groups on the YPAS total time or YPAS energy expenditure. Compared to the control, the treatment group had greater increases in ERA total and mental health scores at 12 months.

\section{Discussion}

The ¡Caminemos! community-based randomized trial is the first study to show that attribution retraining works in increasing walking behavior in older Hispanic/Latino adults. Based on both objective and self-reported measures, we found that participants in both arms of the intervention increased their physical activity throughout the study to favorable levels [89] and that those exposed to the attribution retraining experienced greater increases at 12 months than the controls. Such improvements are notable given the low levels of acculturation observed in the sample-a datum further corroborated by the nativity and preferred language of the participants. The fact that older Hispanic/Latino adults, regardless of socioeconomic status, low levels of acculturation, and the presence of preexisting chronic diseases, responded to a low-cost exercise program suggests a promising cost-saving strategy for promoting their general health.

Additional strengths of the study are also notable. It is one of the few studies to include a substantial number of community-dwelling, urban, older Hispanic/Latino adults [90]. The use of objective and subjective measures heightens the validity of the finding that the participants had significantly improved their activity throughout the study. Such a finding suggests that at least among older Hispanic/Latino adults, disparities in physical activity can be reduced by the availability of fitness programs, environments, and social supports that promote physical movement. Such programs go a long way toward undermining the notion that the aging process includes assuming insufficient levels of physical activity.

Elsewhere, we have also noted the beneficial effects of this increased physical activity on cognitive function

Table 5 Descriptive statistics for the outcome measures at baseline and at 1, 12, and 24 months for treatment and control groups: 24-month follow-up

\begin{tabular}{|c|c|c|c|c|c|c|c|}
\hline \multirow[t]{2}{*}{ Outcomes } & \multicolumn{2}{|l|}{ Control } & \multicolumn{2}{|c|}{ Treatment } & \multicolumn{2}{|c|}{ Difference between two groups } & \multirow[t]{2}{*}{$p$} \\
\hline & Mean & $95 \% \mathrm{Cl}$ & Mean & $95 \% \mathrm{Cl}$ & Mean & $95 \% \mathrm{Cl}$ & \\
\hline Pedometer & $10,593.9$ & $(9703.6,11,484.1)$ & 11,604 & $(10,802.3,12,405.2)$ & -1009.9 & $(-2200.9,181.2)$ & 0.0963 \\
\hline YPAS -Total time & 11.6 & $(10.7,12.6)$ & 12.3 & $(11.1,13.4)$ & -0.6 & $(-2.2,0.9)$ & 0.415 \\
\hline YPAS - Energy expenditure & 2504.3 & $(2253.1,2755.6)$ & 2724 & $(2416.6,3031.5)$ & -219.7 & $(-616.8,177.4)$ & 0.2774 \\
\hline YPAS -Activity dimensions & 42.3 & $(39.3,45.2)$ & 44.8 & $(41.6,47.9)$ & -2.5 & $(-6.8,1.8)$ & 0.2609 \\
\hline ERA - Total score & 39.8 & $(36.1,43.6)$ & 42.4 & $(39.0,45.8)$ & -2.6 & $(-7.6,2.5)$ & 0.3246 \\
\hline ERA - Physical health scale & 35.7 & $(31.6,39.7)$ & 38.4 & $(34.6,42.3)$ & -2.8 & $(-8.4,2.8)$ & 0.3274 \\
\hline ERA - Mental health scale & 52.6 & $(47.8,57.3)$ & 55.6 & $(51.2,59.9)$ & -3.0 & $(-9.4,3.4)$ & 0.3593 \\
\hline ERA - Cognitive function scale & 31.3 & $(27.1,35.4)$ & 33.1 & $(29.4,36.9)$ & -1.9 & $(-7.5,3.7)$ & 0.5147 \\
\hline Exercise self-efficacy & 8.7 & $(8.3,9.0)$ & 8.8 & $(8.5,9.2)$ & -0.2 & $(-0.7,0.3)$ & 0.429 \\
\hline Outcome expectation for exercise & 4.8 & $(4.7,4.8)$ & 4.8 & $(4.7,4.8)$ & 0.0 & $(-0.1,0)$ & 0.4441 \\
\hline
\end{tabular}




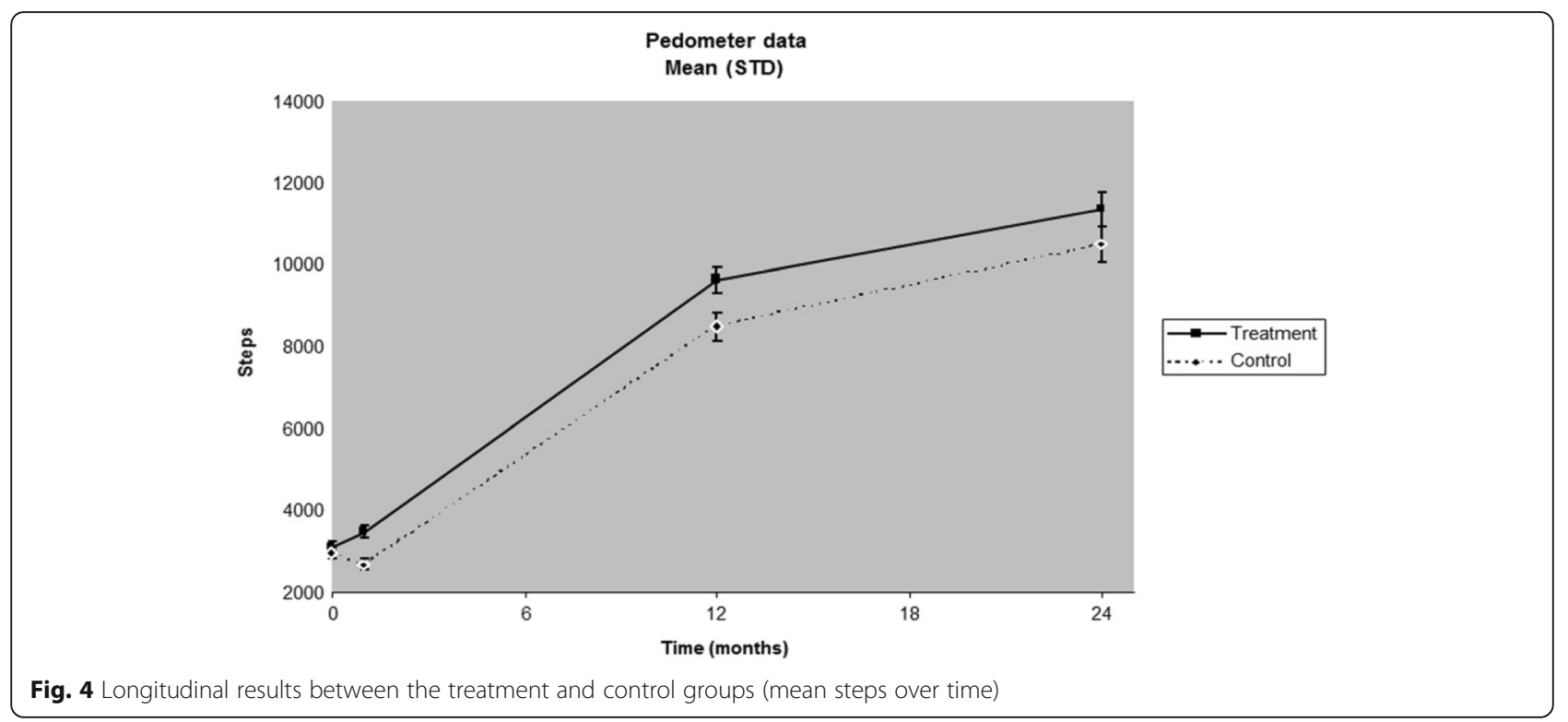

across both arms of the study over time, regardless of whether the participants'exercise program was supplemented with the age-related attribution retraining [60]. We maintained that such improvements are particularly notable for those on the cusp of clinically significant cognitive impairment; small changes can affect the extent to which one is disabled and for how long one lives with that disability [60]. Similarly, in this study we found that physical activity was also associated with increased mental health over time across both groups, regardless of whether the participants received the attribution intervention. This finding is consist with other studies that have observed the cascading effects of physical activity on wellbeing through its association with better mood, emotional function and mental-health outcomes [91-93]. Moreover, we found that older adults exposed to the age-reattribution intervention showed greater mental health improvements, compared to the controls, by 12 -months. In sum, the results from this study are consistent with recent evidence that shows how positive habitual expectations can bolster exercise-induced psychological benefits (impart more enjoyment, improve mood, and reduce anxiety) and facilitate neurophysiological changes by increasing alpha- 2 power, as assessed with electroencephalography [94].

Results also indicate that providing opportunities for physical activity are associated with increases in self-efficacy and outcome expectations for exercise. These findings confirm previous studies have shown that physical activity can enhance self-efficacy among older adults, particularly during the intervention [54]. It also has important implications, as older adults with higher levels of physical activity and self-efficacy are more likely to remain physically active [95]. Levels of outcome expectations for exercise also increased during the study, but previous evidence indicate that self-efficacy tends to be more central for the adhering to physical activity than the expectation of outcome [96]. Nonetheless, both indicators increased during the study. However, contrary to our expectations, these increases were similar in both arms of the study and we expected them to be higher among those exposed to the age-reattribution given that it was developed with combination of social cognition theory and attribution theory.

The striking improvement in physical activity across both arms of the intervention warrants further explanation and underscores the limits of the study. Arguably, the benefits of participating in an exercise program muted the benefits of the attribution-retraining program by the 24-month mark. This finding contradicts our expectations and findings from previous studies, which have found that older adults with low age-expectations had lower levels of physical activity [40], and those with more positive views about aging were less likely to reduce their physical activity over time [97]. In fact, older adults with positive stereotypes about aging often have better physical performance, including walking speed [98]. Wolff and colleagues (2014) report the findings of another randomized control trial in which a physical activity intervention was combined with a component of improving positive views on aging [99]. They report that older adults in the experimental group who were exposed to the 'views-on-aging' component had more positive views about aging and had increased their physical activity at 10-months [99]. Our results point to similar findings at 12-months in which we report higher expectations regarding aging, better mental health and higher number of steps among older adults in the age-reattribution group, however our study had a longer follow-up and we were able to see that these effects did not last at 24-months. 
Table 6 Estimated parameters from repeated mixed-effects regressions on selected outcomes

\begin{tabular}{|c|c|c|c|c|c|c|c|c|}
\hline & \multicolumn{2}{|l|}{ Pedometer } & \multicolumn{2}{|c|}{ YPAS -Total time } & \multicolumn{2}{|c|}{$\begin{array}{l}\text { YPAS - Energy } \\
\text { expenditure }\end{array}$} & \multicolumn{2}{|c|}{ YPAS -Activity dimensions } \\
\hline & Coefficient & $95 \% \mathrm{Cl}$ & Coefficient & $95 \% \mathrm{Cl}$ & Coefficient & $95 \% \mathrm{Cl}$ & Coefficient & $95 \% \mathrm{Cl}$ \\
\hline \multicolumn{9}{|l|}{ Fixed effects } \\
\hline Intervention (ref = control) & 80.7 & -553.5715 .0 & 0.6 & $-0.5,1.7$ & 146.3 & -136.9429 .5 & 2.5 & $-1.1,6.1$ \\
\hline \multicolumn{9}{|l|}{ Month } \\
\hline 1 & -355 & -963.3253 .4 & -0.2 & $-1.1,0.6$ & -51.5 & -278.1175 .1 & $5.8^{* * *}$ & $2.6,9.0$ \\
\hline 12 & $5090.4^{* * *}$ & $4440.6,5740.1$ & 0 & $-0.9,0.9$ & -24.6 & -266.8217 .5 & 3.3 & $-0.1,6.7$ \\
\hline 24 & $7492.2^{* * *}$ & $6796.0,8188.3$ & 0.6 & $-0.3,1.6$ & 93.6 & -156.7343 .9 & $6.7^{* * *}$ & $3.2,10.2$ \\
\hline \multicolumn{9}{|l|}{ Group $\times$ month } \\
\hline Treatment $\times 1$ & 661.8 & $-210.5,1534.1$ & -0.1 & $-1.3,1.1$ & -42.8 & $-369.0,283.5$ & -1.6 & $-6.3,3.0$ \\
\hline Treatment $\times 12$ & $1094.3^{*}$ & $168.4,2020.2$ & -0.6 & $-1.9,0.7$ & -173.1 & -518.5172 .2 & -0.2 & $-5.0,4.7$ \\
\hline Treatment $\times 24$ & 831.8 & $-145.4,1808.9$ & 0.1 & $-1.2,1.4$ & 49.5 & -303.5402 .4 & -0.9 & $-5.8,4.1$ \\
\hline Age & $-889.3^{* * *}$ & $-1319.6,-459.1$ & $-2.5^{* * *}$ & $-3.3,-1.6$ & $-558.4^{* * *}$ & $-784.1,-332.6$ & $-3.0^{*}$ & $-5.5,-0.5$ \\
\hline Female (ref = male) & $-666.1^{*}$ & $-1180.5,-151.7$ & $2.2^{* * *}$ & $1.1,3.2$ & 258 & -12.7528 .7 & $-4.4^{* *}$ & $-7.5,-1.4$ \\
\hline \multicolumn{9}{|l|}{ Education (ref = no schooling) } \\
\hline$\leq 8$ th grade & -158.2 & -776.7460 .3 & 0.8 & $-0.4,2.1$ & 213.7 & $-109.0,536.3$ & $4.3^{*}$ & $0.7,7.9$ \\
\hline Some high school or more/other & -248.3 & -906.9410 .3 & $1.8^{* *}$ & $0.4,3.2$ & $423.8^{*}$ & 78.9768 .7 & $4.9^{*}$ & $1.0,8.8$ \\
\hline \multicolumn{9}{|l|}{ Marital status (ref = never married) } \\
\hline Married & -56.9 & $-754.0,640.3$ & 0.8 & $-0.7,2.2$ & 271.5 & -95.7638 .6 & 2 & $-2.1,6.2$ \\
\hline Separated/divorced & -44 & -756.9668 .8 & 0.2 & $-1.3,1.6$ & 36.4 & $-337.0,409.8$ & $4.4^{*}$ & $0.2,8.6$ \\
\hline Widowed & 236.7 & -431.1904 .5 & 0.2 & $-1.2,1.6$ & 30.2 & -319.6380 .0 & 0.1 & $-3.8,4.0$ \\
\hline \multicolumn{9}{|l|}{ Income (ref = less than $\$ 20,000)$} \\
\hline$\$ 20,000$ or more & 63.5 & -512.9640 .0 & -0.2 & $-1.4,1.1$ & 16.8 & -290.4324 .0 & 0.1 & $-3.3,3.6$ \\
\hline Missing & 490.4 & $-241.0,1221.7$ & -0.9 & $-2.4,0.7$ & -225.3 & -610.6159 .9 & -2 & $-6.3,2.3$ \\
\hline Medical comorbidities & $-180.6^{*}$ & $-328.8,-32.5$ & -0.1 & $-0.4,0.2$ & -40.4 & $-117.9,37.1$ & -0.3 & $-1.2,0.6$ \\
\hline \multicolumn{9}{|c|}{ Body mass index (ref = underweight/normal) } \\
\hline Overweight & -455 & -1054.8144 .9 & 0.2 & $-1.1,1.5$ & 52.9 & -263.6369 .5 & -1.7 & $-5.2,1.9$ \\
\hline Obese & $-605.0^{*}$ & $-1197.7,-12.4$ & -0.1 & $-1.3,1.1$ & -45.3 & -358.5267 .9 & -1.9 & $-5.4,1.6$ \\
\hline SF-12 Physical & $23.8^{*}$ & $2.3,45.4$ & $0.1^{* * *}$ & $0.1,0.2$ & $32.6^{* * *}$ & $21.3,44.0$ & $0.3^{* * *}$ & $0.2,0.4$ \\
\hline SF-12 Mental & 7.1 & $-12.7,26.9$ & $0.1^{*}$ & $0.0,0.1$ & 10.2 & $-0.2,20.7$ & 0 & $-0.1,0.1$ \\
\hline Acculturation & -28.1 & $-195.0,138.9$ & 0 & $-0.3,0.4$ & 31.7 & -56.4119 .8 & -0.5 & $-1.5,0.5$ \\
\hline Intercept & $3642.0^{* * *}$ & $1742.4,5541.6$ & 1.2 & $-2.7,5.2$ & 223.2 & $-771.6,1218.0$ & $24.6^{* * *}$ & $13.4,35.8$ \\
\hline \multicolumn{9}{|l|}{ Random effects } \\
\hline Intercept & $7.2^{* * *}$ & $7.0,7.4$ & $1.4^{* * *}$ & $1.3,1.5$ & $6.9^{* * *}$ & $6.8,7.0$ & $2.3^{* * *}$ & $2.1,2.4$ \\
\hline Residual & $8.2^{* * *}$ & $8.1,8.2$ & $1.6^{* * *}$ & $1.6,1.7$ & $7.2^{* * *}$ & $7.2,7.3$ & $3.0^{* * *}$ & $2.9,3.0$ \\
\hline \multirow[t]{3}{*}{ Sample size } & 1780 & & 1955 & & 1955 & & 1953 & \\
\hline & \multicolumn{2}{|c|}{ ERA - Total score } & \multicolumn{2}{|c|}{$\begin{array}{l}\text { ERA - Physical health } \\
\text { scale }\end{array}$} & \multicolumn{2}{|c|}{ ERA - Mental health scale } & \multicolumn{2}{|c|}{$\begin{array}{l}\text { ERA - Cognitive function } \\
\text { scale }\end{array}$} \\
\hline & Coefficient & $95 \% \mathrm{Cl}$ & Coefficient & $95 \% \mathrm{Cl}$ & Coefficient & $95 \% \mathrm{Cl}$ & Coefficient & $95 \% \mathrm{Cl}$ \\
\hline \multicolumn{9}{|l|}{ Fixed effects } \\
\hline Intervention (ref = control) & -1.4 & $-4.6,1.8$ & -1 & $-4.7,2.8$ & -3 & $-7.2,1.2$ & -0.2 & $-4.1,3.6$ \\
\hline \multicolumn{9}{|l|}{ Month } \\
\hline 1 & $3.4^{* *}$ & $1.0,5.8$ & $4.0^{* *}$ & $1.0,7.1$ & $3.5^{*}$ & $0.3,6.6$ & 2.8 & $-0.1,5.8$ \\
\hline 12 & 2.5 & $-0.0,5.1$ & 3.3 & $-0.0,6.6$ & 1.6 & $-1.8,5.0$ & 2.6 & $-0.6,5.8$ \\
\hline 24 & $3.6^{* *}$ & $0.9,6.2$ & $4.4^{*}$ & $1.0,7.8$ & $5.7^{* *}$ & $2.2,9.2$ & 0.6 & $-2.6,3.9$ \\
\hline
\end{tabular}


Table 6 Estimated parameters from repeated mixed-effects regressions on selected outcomes (Continued)

\begin{tabular}{|c|c|c|c|c|c|c|c|c|}
\hline & \multicolumn{2}{|l|}{ Pedometer } & \multicolumn{2}{|c|}{ YPAS -Total time } & \multicolumn{2}{|c|}{$\begin{array}{l}\text { YPAS - Energy } \\
\text { expenditure }\end{array}$} & \multicolumn{2}{|c|}{ YPAS -Activity dimensions } \\
\hline & Coefficient & $95 \% \mathrm{Cl}$ & Coefficient & $95 \% \mathrm{Cl}$ & Coefficient & $95 \% \mathrm{Cl}$ & Coefficient & $95 \% \mathrm{Cl}$ \\
\hline \multicolumn{9}{|l|}{ Group $\times$ month } \\
\hline Treatment $\times 1$ & 1.8 & $-1.6,5.3$ & 1.9 & $-2.6,6.3$ & 3.6 & $-0.9,8.2$ & 0 & $-4.3,4.2$ \\
\hline Treatment $\times 12$ & $4.2^{*}$ & $0.6,7.8$ & 2.3 & $-2.4,7.0$ & $9.7^{* * *}$ & $4.9,14.5$ & 0.8 & $-3.7,5.3$ \\
\hline Treatment $\times 24$ & 3.2 & $-0.5,6.9$ & 3.6 & $-1.1,8.4$ & 4.8 & $-0.1,9.8$ & 1.2 & $-3.4,5.8$ \\
\hline Age & $-6.0^{* * *}$ & $-8.8,-3.3$ & $-6.7^{* * *}$ & $-9.7,-3.8$ & $-6.1^{* * *}$ & $-9.6,-2.6$ & $-5.3^{* * *}$ & $-8.5,-2.2$ \\
\hline Female (ref = male) & $4.9^{* *}$ & $1.6,8.2$ & 2.7 & $-0.8,6.3$ & $8.5^{* * *}$ & $4.3,12.7$ & 3.4 & $-0.4,7.2$ \\
\hline \multicolumn{9}{|l|}{ Education (ref = no schooling) } \\
\hline$\leq 8$ th grade & $7.9^{* * *}$ & $4.0,11.8$ & $7.9^{* * *}$ & $3.6,12.1$ & $10.3^{* * *}$ & $5.3,15.3$ & $5.4^{*}$ & $1.0,9.9$ \\
\hline Some high school or more/other & $12.3^{* * *}$ & $8.1,16.4$ & $10.4^{* * *}$ & $5.9,14.9$ & $17.6^{* * *}$ & $12.3,23.0$ & $8.9^{* * *}$ & $4.1,13.7$ \\
\hline \multicolumn{9}{|l|}{ Marital status $($ ref $=$ never married $)$} \\
\hline Married & -1.2 & $-5.6,3.3$ & -2.3 & $-7.1,2.5$ & 0.8 & $-4.9,6.4$ & -2.3 & $-7.4,2.9$ \\
\hline Separated/divorced & 0.5 & $-4.1,5.0$ & 0.2 & $-4.7,5.1$ & 1.8 & $-4.0,7.6$ & -0.8 & $-6.0,4.4$ \\
\hline Widowed & 0.3 & $-4.0,4.5$ & -0.4 & $-5.0,4.2$ & 1.5 & $-3.9,6.9$ & -0.4 & $-5.3,4.5$ \\
\hline \multicolumn{9}{|l|}{ Income (ref = less than $\$ 20,000$ ) } \\
\hline$\$ 20,000$ or more & 1.7 & $-2.0,5.5$ & 2.6 & $-1.4,6.6$ & 2.9 & $-1.8,7.7$ & -0.5 & $-4.8,3.7$ \\
\hline Missing & 3.1 & $-1.6,7.7$ & 2.1 & $-2.9,7.1$ & 5.1 & $-0.8,11.1$ & 2.1 & $-3.2,7.5$ \\
\hline Medical comorbidities & -0.6 & $-1.5,0.4$ & -0.6 & $-1.6,0.5$ & -0.6 & $-1.8,0.6$ & -0.6 & $-1.7,0.5$ \\
\hline \multicolumn{9}{|c|}{ Body mass index (ref = underweight/normal) } \\
\hline Overweight & -1.2 & $-5.0,2.7$ & -3.3 & $-7.4,0.9$ & -1 & $-5.9,3.9$ & 0.8 & $-3.6,5.2$ \\
\hline Obese & 0.2 & $-3.6,4.0$ & -0.8 & $-4.8,3.3$ & 0.1 & $-4.8,4.9$ & 1.3 & $-3.0,5.7$ \\
\hline SF-12 Physical & $0.4^{* * *}$ & $0.3,0.5$ & $0.4^{* * *}$ & $0.3,0.6$ & $0.5^{* * *}$ & $0.3,0.6$ & $0.3^{* * *}$ & $0.1,0.5$ \\
\hline SF-12 Mental & $0.4^{* * *}$ & $0.3,0.6$ & $0.3^{* * *}$ & $0.1,0.4$ & $0.7^{* * *}$ & $0.5,0.8$ & $0.3^{* * *}$ & $0.2,0.5$ \\
\hline Acculturation & 0.8 & $-0.2,1.9$ & -0.1 & $-1.3,1.0$ & 1.3 & $-0.1,2.6$ & $1.4^{*}$ & $0.1,2.6$ \\
\hline Intercept & $-12.2^{*}$ & $-24.2,-0.1$ & -3.2 & $-16.2,9.8$ & $-25.6^{* *}$ & $-41.0,-10.2$ & -7.4 & $-21.2,6.4$ \\
\hline \multicolumn{9}{|l|}{ Random effects } \\
\hline Intercept & $2.6^{* * *}$ & $2.5,2.7$ & $2.6^{* * *}$ & $2.5,2.7$ & $2.8^{* * *}$ & $2.7,2.9$ & $2.7^{* * *}$ & $2.6,2.8$ \\
\hline Residual & $2.7^{* * *}$ & $2.6,2.7$ & $2.9^{* * *}$ & $2.9,3.0$ & $2.9^{* * *}$ & $2.9,3.0$ & $2.9^{* * *}$ & $2.8,2.9$ \\
\hline \multirow[t]{3}{*}{ Sample size } & \multirow{3}{*}{\multicolumn{2}{|c|}{1956}} & \multicolumn{2}{|l|}{1956} & \multicolumn{2}{|l|}{1956} & \multicolumn{2}{|l|}{1955} \\
\hline & & & \multicolumn{2}{|c|}{ Exercise self-efficacy } & \multicolumn{4}{|c|}{ Outcome expectation for exercise } \\
\hline & & & Coefficient & $95 \% \mathrm{Cl}$ & Coefficient & & $95 \% \mathrm{Cl}$ & \\
\hline \multicolumn{9}{|l|}{ Fixed effects } \\
\hline Intervention (ref = control) & & & -0.2 & $-0.5,0.2$ & 0.0 & & $-0.1,0.1$ & \\
\hline \multicolumn{9}{|l|}{ Month } \\
\hline 1 & & & 0.2 & $-0.0,0.4$ & $0.2^{* * *}$ & & $0.1,0.3$ & \\
\hline 12 & & & $0.3^{*}$ & $0.0,0.5$ & $0.2^{* * *}$ & & $0.1,0.3$ & \\
\hline 24 & & & $0.4^{* *}$ & $0.1,0.6$ & $0.3^{* * *}$ & & $0.2,0.3$ & \\
\hline \multicolumn{9}{|l|}{ Group x month } \\
\hline Treatment $\times 1$ & & & 0.2 & $-0.2,0.5$ & 0.0 & & $-0.1,0.1$ & \\
\hline Treatment $\times 12$ & & & 0.0 & $-0.3,0.4$ & 0.0 & & $-0.1,0.1$ & \\
\hline Treatment $\times 24$ & & & 0.4 & $-0.0,0.7$ & 0.1 & & $-0.0,0.2$ & \\
\hline Age & & & $-0.9^{* * *}$ & $-1.2,-0.6$ & 0.0 & & $-0.1,0.0$ & \\
\hline Female (ref = male) & & & -0.1 & $-0.4,0.2$ & 0.0 & & $-0.0,0.1$ & \\
\hline
\end{tabular}


Table 6 Estimated parameters from repeated mixed-effects regressions on selected outcomes (Continued)

\begin{tabular}{|c|c|c|c|c|c|c|c|c|}
\hline & \multicolumn{2}{|l|}{ Pedometer } & \multicolumn{2}{|c|}{ YPAS -Total time } & \multicolumn{2}{|c|}{$\begin{array}{l}\text { YPAS - Energy } \\
\text { expenditure }\end{array}$} & \multicolumn{2}{|c|}{ YPAS -Activity dimensions } \\
\hline & Coefficient & $95 \% \mathrm{Cl}$ & Coefficient & $95 \% \mathrm{Cl}$ & Coefficient & $95 \% \mathrm{Cl}$ & Coefficient & $95 \% \mathrm{Cl}$ \\
\hline \multicolumn{9}{|l|}{ Education (ref = no schooling) } \\
\hline$\leq 8$ th grade & & & 0.2 & $-0.2,0.6$ & 0.0 & & $-0.1,0.1$ & \\
\hline Some high school or more/other & & & 0.4 & $-0.0,0.8$ & -0.1 & & $-0.2,0.0$ & \\
\hline \multicolumn{9}{|l|}{ Marital status (ref = never married) } \\
\hline Married & & & 0 & $-0.5,0.4$ & 0.0 & & $-0.1,0.1$ & \\
\hline Separated/divorced & & & 0.2 & $-0.2,0.7$ & 0.0 & & $-0.1,0.1$ & \\
\hline Widowed & & & -0.2 & $-0.6,0.2$ & 0.0 & & $-0.1,0.1$ & \\
\hline \multicolumn{9}{|l|}{ Income (ref = less than $\$ 20,000)$} \\
\hline$\$ 20,000$ or more & & & 0.2 & $-0.1,0.6$ & 0.1 & & $-0.0,0.1$ & \\
\hline Missing & & & 0.1 & $-0.4,0.6$ & $0.1^{*}$ & & $0.0,0.2$ & \\
\hline Medical comorbidities & & & -0.1 & $-0.2,0.0$ & 0.0 & & $-0.0,0.0$ & \\
\hline \multicolumn{9}{|c|}{ Body mass index (ref = underweight/normal) } \\
\hline Overweight & & & -0.3 & $-0.7,0.1$ & 0.0 & & $-0.1,0.1$ & \\
\hline Obese & & & -0.3 & $-0.7,0.1$ & 0.0 & & $-0.1,0.1$ & \\
\hline SF-12 Physical & & & $0.1^{* * *}$ & $0.1,0.1$ & $0.0^{* *}$ & & $0.0,0.0$ & \\
\hline SF-12 Mental & & & $0.0^{*}$ & $0.0,0.0$ & $0.0^{* * *}$ & & $0.0,0.0$ & \\
\hline Acculturation & & & 0.0 & $-0.2,0.1$ & 0.0 & & $-0.0,0.0$ & \\
\hline Intercept & & & $5.0^{* * *}$ & $3.8,6.2$ & $4.0^{* * *}$ & & $3.8,4.3$ & \\
\hline \multicolumn{9}{|l|}{ Random effects } \\
\hline Intercept & & & $0.3^{* * *}$ & $0.2,0.3$ & $-1.4^{* * *}$ & & $-1.5,-1.3$ & \\
\hline Residual & & & $0.4^{* * *}$ & $0.3,0.4$ & $-0.9^{* * *}$ & & $-0.9,-0.8$ & \\
\hline Sample size & & & 1893 & & 1955 & & & \\
\hline
\end{tabular}

${ }^{* * *} p<0.001 ;{ }^{* *} p<0.01 ;{ }^{*} p<0.05$

Regardless of how one feels about the aging process, the act of participating in an exercise program may have superseded any latent feelings of aging with manifest behavior and created a situation in which both the control and treatment groups benefitted from the exercise program. Such a situation is consistent with attribution theory in which the behavior (exercising) alters thinking (one can be active) and this cognitive change reinforces future behavior $[49,51,52]$. Moreover, we speculate that in this context, the health lectures administered to the control group functioned similarly to the reattribution classes that the treatment group received; both the health lectures and the intervention ultimately reinforced the association between health and physical

Table 7 Predicted mean number of steps and differences over time in the ¡Caminemos! study

\begin{tabular}{|c|c|c|c|c|c|c|c|}
\hline & Predicted mean number of steps & $95 \% \mathrm{Cl}$ & & Differences to baseline & $95 \% \mathrm{Cl}$ & & $p$-value \\
\hline \multicolumn{8}{|l|}{ Control } \\
\hline Baseline & 3058 & 2616 & 3500 & & & & \\
\hline Month 1 & 2702 & 2233 & 3171 & -356 & -964 & 252 & 0.251 \\
\hline Month 12 & 8157 & 7635 & 8679 & 5099 & 4450 & 5749 & $<0.0001$ \\
\hline Month 24 & 10,564 & 9986 & 11,142 & 7506 & 6810 & 8201 & $<0.0001$ \\
\hline \multicolumn{8}{|l|}{ Treatment } \\
\hline Baseline & 3133 & 2681 & 3585 & & & & \\
\hline Month 1 & 3440 & 2956 & 3924 & 307 & -318 & 932 & 0.336 \\
\hline Month 12 & 9323 & 8796 & 9850 & 6190 & 5531 & 6850 & $<0.0001$ \\
\hline Month 24 & 11,458 & 10,898 & 12,018 & 8325 & 7639 & 9011 & $<0.0001$ \\
\hline
\end{tabular}


exercise. Thus, irrespective of any preconceived notions about age and physical activity, the idea that movement contributes to greater health infused both arms of the intervention and seemed to stick [100]. This dynamic is a limitation of the study design and occurred without reinforcing the content provided to the controls in the health lectures; it would be interesting to know whether repeating the allocutions given to the control group (rather than giving new lectures) would have made a difference between the intervention and the control group. These findings underscore how environmental cues shape thoughts and behavior, and are consistent with other studies that have observed that perceived neighborhood safety and proximity to resources within a community improved levels of physical activity [34, 35, 90, 101]. Accordingly, this study is limited by the absence of a comparison with a true control group-one in which inactive participants received neither an exercise class nor any form of cognitive support. However, such an experiment would raise ethical concerns that our community partners would find untenable.

Throughout this study, we concentrated our efforts on those seniors most in need of starting a walking program; however, such a focus meant that we excluded potential participants who surpassed our activity thresholds (20 min 3xs per week) but who remained well below the recommended levels of physical activity (150 min of moderate intensity activity accumulatively over the week). These semi-active seniors might also have benefited from the intervention; further research should examine whether this intervention can succeed in this more active group. Another useful comparison would have been between groups of elders who already engaged in regular activity at a minimum recommended threshold, usually between 7000 and 10,000 steps [89] and who were randomly assigned to receive the reattribution training or the health lectures. Such a comparison would be useful in understanding the motivating role of the attribution-retraining intervention. In addition, because the data collection ended after 24 months, we have no way of knowing if those who received the attribution retraining might have had an advantage in maintaining their physical activity in the long term.

These results must be appraised within the context of some further limitations. Randomization occurred at the individual-level, which increased the risk for contamination. However, this limitation was weighed against three problems that randomizing by site would pose. First, a heterogeneous Latino population in greater Los Angeles led to sites that differed vastly, especially in regards to physical infrastructure and participant socioeconomic status. The presence of such diversity, stratified by location, would have led us to question whether the observed findings were due to differences between sites rather than the intervention itself.
Second, randomization by place would have meant that those sites assigned to a control group would not receive the full intervention, a very unattractive prospect to community partners. Finally, the study would have required a much larger sample size. Taken together, we concluded that the complications created by randomization at the site-level outweighed any contamination issues that might occur (but could be minimized) when randomizing at the individual level. Future studies should measure the impact of the intervention in the context of a larger evaluation framework such as RE-AIM. [102-104]

Another limitation refers to the use of pedometer data to assess step counts. Evidence suggests that, compared to accelerometers, pedometers tend to underestimate the number of steps at lower speeds, which can be a problem when studying frail older adults [105]. In particular, pedometers have problems estimating step counts when individuals have variable gait patterns, which tend to be more common among nursing home residents than among community-dwellers [106]. Therefore, the use of pedometers has shown to be appropriate among community-dweller older adults, although it may be associated with an underestimation in the number of steps [106]. Our estimates based on the pedometer data should be taken as conservative estimates as they may underestimate the real number of steps (by 7-25\%) [106] in both arms of the study. Although multiple measures were used, the self-report instruments were administered repeatedly and therefore were vulnerable to repeat testing bias. The responses might have been affected by memory or by a wish to present oneself in a socially acceptable manner, which may include reporting what is perceived as desirable. These factors can lead people to overestimate or underestimate data and bias the results. In addition, we did not include any clinically objective biomarkers that would correspond with enhanced physical fitness. Nonetheless, well-validated instruments were used that have been known to yield robust findings with an understudied population. Moreover, the use of the pedometer data and a consistent pattern of improvement for all measures across the intervention arms indicated that the repeat testing bias exerted a minimal effect. Data on chronic conditions were only available at baseline; therefore, it was not possible to evaluate how they might have influenced the outcomes over the duration of the study. Finally, women composed most of our sample, so one should be cautious when generalizing our findings.

\section{Conclusion}

Overall, although participants in both arms of the intervention benefitted from the exercise intervention, those exposed to attribution retraining outperformed those who received only the exercise program by 12 months. As the Latino population is expected to grow exponentially over 
the coming decades, increasing physical activity may be a powerful cost-saving strategy for improving the health of older Hispanic/Latino adults, regardless of socioeconomic status, low levels of acculturation, and the presence of preexisting chronic diseases.

\section{Abbreviations}

BMI: Body mass index; ERA-12: Expectations Regarding Aging;

IRB: Institutional Review Board; OEE: Outcome Expectation for Exercise Scale; SASH: Short Acculturation Scale for Hispanics; SF-12: 12-Item Short-Form Health Survey; YPAS: Yale Physical Activity Survey

\section{Acknowledgments}

The authors are very grateful to the leadership and staff of the 27 senior centers that collaborated with us on ¡Caminemos!

\section{Funding}

This work was supported by the National Institute on Aging of the National Institutes of Health (R01 AG024460-05 to C. A. Sarkisian); the UCLA Claude D. Pepper Older Americans Independence Center (P30AG028748 to C. A Sarkisian); and the Midcareer Award in Patient-Oriented CommunityAcademic Partnered Aging Research (1K24AG047899-02 to C. A. Sarkisian). R. Hernandez is funded by the National Heart, Lung, and Blood Institute (NHLBI) through award number 1K01HL13071201A1.

\section{Availability of data and materials}

The dataset supporting the conclusions of this article is available by request to Dr. Sarkisian csarkisian@mednet.ucla.edu.

\section{Authors' contributions}

CAS designed the study and supervised the data collection. TRP consulted on the study design and the implementation of the intervention. LT coordinated the data collection. All three aforementioned authors contributed to the interpretation of the findings. LMP produced the first draft of the manuscript, coordinated with coauthors, contributed to and edited subsequent iterations. FCDA lead the statistical analysis. LMP, CAS and FCDA contributed to the analysis and interpretations of the findings. $\mathrm{RH}$ contributed to the introduction and methods section. FCDA contributed to the results and discussion section. CAS consulted on each section of the paper and on the presentation of results. All authors read and approved the final manuscript.

\section{Ethics approval and consent to participate}

Approval for the study was obtained through the Institutional Review Board of the University of Los Angeles with written informed consent provided by all enrolled participants.

\section{Consent for publication}

Not applicable.

\section{Competing interests}

All authors declare that they have no competing interests.

\section{Publisher's Note}

Springer Nature remains neutral with regard to jurisdictional claims in published maps and institutional affiliations.

\section{Author details}

${ }^{1}$ School of Social Work, University of Illinois at Urbana-Champaign, 1010 West Nevada St, Urbana, IL 61801, USA. ${ }^{2}$ Kinesiology \& Community Health, College of Applied Health Sciences, University of Illinois at Urbana-Champaign, Champaign, IL, USA. ${ }^{3}$ City of Los Angeles Department of Aging, Los Angeles, CA, USA. ${ }^{4}$ College of Health and Human Services, George Mason University, Fairfax, VA, USA. ${ }^{5}$ David Geffen School of Medicine at UCLA, Los Angeles, CA, USA. ${ }^{6}$ VA Greater Los Angeles Geriatric Research Education and Clinical Center, Los Angeles, CA, USA.
Received: 6 November 2017 Accepted: 13 July 2018

Published online: 03 August 2018

\section{References}

1. U.S. Department of Health and Human Services, Office of Disease Prevention and Health Promotion Healthy People 2020 [Internet]. https://www. healthypeople.gov/. Accessed 24 Oct 2017.

2. U.S. Department of Health and Human Services, Office of Disease Prevention and Health Promotion. Healthy People 2020 [Internet]. Available from: https:// www.healthypeople.gov/2020/data-search/Search-the-Data\#objid=4981. Accessed 24 Oct 2017.

3. Matthews CE, Chen KY, Freedson PS, Buchowski MS, Beech BM, Pate RR, et al. Amount of time spent in sedentary behaviors in the United States, 2003-2004. Am J Epidemiol. 2008;167(7):875-81.

4. Davis MG, Fox KR, Hillsdon M, Sharp DJ, Coulson JC, Thompson JL. Objectively measured physical activity in a diverse sample of older urban UK adults. Med Sci Sports Exerc. 2001;43(4):647-54.

5. McLennan W, Podger A. National nutrition survey users' guide. In: Catalogue No 48010. Canberra: ACT: Australian Bureau of Statistics; 1998.

6. Pate RR, O'Neill JR, Lobelo F. The evolving definition of "sedentary". Exerc Sport Sci Rev. 2008;36(4):173-8.

7. Biswas A, Oh PI, Faulkner GE, Bajaj RR, Silver MA, Mitchell MS, et al, Sedentary time and its association with risk for disease incidence, mortality, and hospitalization in adults: a systematic review and meta-analysis. Ann Intern Med. 2015;162(2):123-32

8. Proper Kl, Singh AS, Van Mechelen W, Chinapaw MJ. Sedentary behaviors and health outcomes among adults: a systematic review of prospective studies. Am J Prev Med. 2011:40(2):174-82.

9. Teychenne M, Ball K, Salmon J. Sedentary behaviour and depression among adults: a review. Int J Behav Med. 2010;17(4):246-54.

10. Edwardson CL, Gorely T, Davies MJ, Gray LJ, Khunti K, Wilmot EG, et al. Association of sedentary behaviour with metabolic syndrome: a metaanalysis. PLoS One. 2012;7(4):e34916.

11. de Rezende LFM, Rey-López JP, Matsudo VKR, do Carmo Luiz O. Sedentary behavior and health outcomes among older adults: a systematic review. BMC Public Health. 2014;14(1):333.

12. Lee IM, Shiroma EJ, Lobelo F, Puska P, Blair SN, Katzmarzyk PT. Effect of physical inactivity on major non-communicable diseases worldwide: an analysis of burden of disease and life expectancy. Lancet. 2012;380(9838): 219-29.

13. Bauman A, Merom D, Bull FC, Buchner DM, Fiatarone Singh MA. Updating the evidence for physical activity: summative reviews of the epidemiological evidence, prevalence, and interventions to promote "active aging". Gerontologist. 2016;56(Suppl 2):S268-80.

14. Buman MP, Hekler EB, Haskell WL, Pruitt L, Conway TL, Cain KL, Sallis JF, Saelens $B E$, Frank LD, King AC. Objective light-intensity physical activity associations with rated health in older adults. Am J Epidemiol. 2010;172(10):1155-65.

15. Yasunaga A, Shibata A, Ishii K, Koohsari MJ, Inoue S, Sugiyama T, Owen N, Oka K. Associations of sedentary behavior and physical activity with older adults' physical function: an isotemporal substitution approach. BMC Geriatr. 2017; 17(1):280

16. Dyck DV, Cerin E, De Bourdeaudhuij I, Hinckson E, Reis RS, Davey R, et al. International study of objectively measured physical activity and sedentary time with body mass index and obesity: IPEN adult study. Int J Obes. 2015;39(2):199-207.

17. Ladabaum U, Mannalithara A, Myer PA, Singh G. Obesity, abdominal obesity, physical activity, and caloric intake in US adults: 1988 to 2010. Am J Med 2014;127(8):717-27. e712.

18. Knowler WC, Barrett-Connor E, Fowler SE, Hamman RF, Lachin JM, Walker $E A$, et al. Reduction in the incidence of type 2 diabetes with lifestyle intervention or metformin. N Engl J Med. 2002;346(6):393-403.

19. World Health Organization. World report on ageing and health. Geneva: World Health Organization; 2015.

20. Ortman Jennifer M, Velkoff Victoria A, Hogan H. An aging nation: the olde population in the United States, current population reports, P25-1140. U.S Census Bureau; Washington, DC: 2014.

21. Administration for Community Living, Administration on Aging. A statistical profile of Hispanic older Americans aged 65+. https://www.acl.gov/sites/ default/files/news\%202017-03/A_Statistical_Profile of Older_Hispanics.pdf. Accessed 24 Oct 2017 
22. Federal Interagency Forum on Aging-Related Statistics. Older Americans 2012: key indicators of well-being. Washington: U.S. Government Printing Office; 2012

23. Crespo CJ, Smit E, Andersen RE, Carter-Pokras O, Ainsworth BE. Race/ ethnicity, social class and their relation to physical inactivity during leisure time: results from the third National Health and nutrition examination survey, 1988-1994. Am J Prev Med. 2000;18(1):46-53.

24. Clark DO. Racial and educational differences in physical activity among older adults. The Gerontologist. 1995;35(4):472-80.

25. Lee DJ, Markides KS. Activity and mortality among aged persons over an eight-year period. J Gerontol. 1990;45(1):S39-42.

26. Keadle SK, McKinnon R, Graubard BI, Troiano RP. Prevalence and trends in physical activity among older adults in the United States: a comparison across three national surveys. Prev Med. 2016;89:37-43.

27. Flegal KM, Carroll MD, Kit BK, Ogden CL. Prevalence of obesity and trends in the distribution of body mass index among US adults, 1999-2010. JAMA. 2012;307(5):491-7.

28. Flegal KM, Kruszon-Moran D, Carroll MD, Fryar CD, Ogden CL. Trends in obesity among adults in the United States, 2005 to 2014. JAMA 2016;315(21):2284-91.

29. Schneiderman N, Llabre M, Cowie CC, Barnhart J, Carnethon M, Gallo LC, Giachello AL, Heiss G, Kaplan RC, LaVange LM, et al. Prevalence of diabetes among Hispanics/Latinos from diverse backgrounds: the Hispanic community health study/study of Latinos (HCHS/SOL). Diabetes Care. 2014;37(8):2233-9.

30. Daviglus ML, Talavera GA, Avilés-Santa ML, Allison M, Cai J, Criqui MH, Gellman M, Giachello AL, Gouskova N, Kaplan RC. Prevalence of major cardiovascular risk factors and cardiovascular diseases among Hispanic/ Latino individuals of diverse backgrounds in the United States. JAMA. 2012;308(17):1775-84.

31. Rodriguez CJ, Allison M, Daviglus ML, Isasi CR, Keller C, Leira EC, Palaniappan L, Pina IL, Ramirez SM, Rodriguez B, et al. Status of cardiovascular disease and stroke in Hispanics/Latinos in the United States: a science advisory from the American Heart Association. Circulation. 2014;130(7):593-625.

32. Angel RJ, Angel JL, Hill TD. Longer lives, sicker lives? Increased longevity and extended disability among Mexican-origin elders. J Gerontol Ser B Psychol Sci Soc Sci. 2015;70(4):639-49.

33. Angel RJ, Angel JL, Diaz Venegas C, Bonazzo C. Shorter stay, longer life: age at migration and mortality among the older Mexican-origin population. J Aging Health. 2010;22(7):914-31.

34. Jurkowski JM, Mosquera M, Ramos B. Selected cultural factors associated with physical activity among Latino women. Women's Health Issues. 2010;20(3):219-26.

35. Levasseur M, Genereux M, Bruneau JF, Vanasse A, Chabot E, Beaulac C, Bedard MM. Importance of proximity to resources, social support, transportation and neighborhood security for mobility and social participation in older adults: results from a scoping study. BMC Public Health. 2015;15:503.

36. Melillo KD, Williamson E, Houde SC, Futrell M, Read CY, Campasano M. Perceptions of older Latino adults regarding physical fitness, physical activity, and exercise. J Gerontol Nurs. 2001;27(9):38-46.

37. Dergance JM, Calmbach WL, Dhanda R, Miles TP, Hazuda HP, Mouton CP. Barriers to and benefits of leisure time physical activity in the elderly: differences across cultures. J Am Geriatr Soc. 2003;51(6):863-8.

38. Sarkisian CA, Shunkwiler SM, Aguilar I, Moore AA. Ethnic differences in expectations for aging among older adults. J Am Geriatr Soc. 2006;54(8):1277-82.

39. Sarkisian CA, Prohaska TR, Davis C, Weiner B. Pilot test of an attribution retraining intervention to raise walking levels in sedentary older adults. J Am Geriatr Soc. 2007;55(11):1842-6.

40. Sarkisian CA, Prohaska TR, Wong MD, Hirsch S, Mangione CM. The relationship between expectations for aging and physical activity among older adults. J Gen Intern Med. 2005;20(10):911-5.

41. Sharkey JR, Sharf BF, St John JA. "Una persona derechita (staying right in the mind)": perceptions of Spanish-speaking Mexican American older adults in South Texas colonias. The Gerontologist. 2009;49(Suppl 1):S79-85.

42. Becker MH. The health belief model and personal health behavior. Health Educ Monogr. 1974;2:324-473.

43. Bandura A. Self-efficacy: the exercise of control. New York: W.H. Freeman; 1997.

44. Prochaska JO, DiClemente CC. Stages and processes of self-change of smoking: toward an integrative model of change. J Consult Clin Psychol. 1983;51:390-5.
45. Ajzen I. The theory of planned behavior. Organ Behav Hum Decis Proceses. 1991;50:179-211.

46. Brawley L, Rejeski W, Lutes L. A group-mediated cognitive-behavorial intervention for increasing adherence to physical activity in older adults. J Appl Biobehav Res. 2000;5:47-65.

47. Elder JP, Williams SJ, Drew JA, Wright BL, Boulan TE. Longitudinal effects of preventive services on health behaviors among an elderly cohort. Am J Prev Med. 1995;11(6):354-9.

48. King AC, Pruitt LA, Phillips W, Oka R, Rodenburg A, Haskell WL. Comparative effects of two physical activity programs on measured and perceived physical functioning and other health-related quality of life outcomes in older adults. J Gerontol A Biol Sci Med Sci. 2000;55(2):M74-83.

49. Conn VS, Minor MA, Burks KJ, Rantz MJ, Pomeroy SH. Integrative review of physical activity intervention research with aging adults. J Am Geriatr Soc. 2003;51(8):1159-68.

50. King AC: Interventions to promote physical activity by older adults. J Gerontol A Biol Sci Med Sci. 2001; 56 (Spec No. 2):36-46.

51. Prohaska T, Lorig K: What do we know about what works? In: Patient Education: A Practical Approach. edn. Edited by Lorig K. Thousand Oaks: Sage Publications, Inc.; 2001: 21-55.

52. Resnick B, Nigg $C$. Testing a theoretical model of exercise behavior for older adults. Nurs Res. 2003;52(2):80-8.

53. McAuley E, Mailey EL, Mullen SP, Szabo AN, Wójcicki TR, White SM, Gothe N, Olson EA, Kramer AF. Growth trajectories of exercise self-efficacy in older adults: influence of measures and initial status. Health Psychol. 2011;30(1):75-83.

54. McAuley E, Blissmer B, Katula J, Duncan TE, Mihalko SL. Physical activity, self-esteem, and self-efficacy relationships in older adults: a randomized controlled trial. Ann Behav Med. 2000;22(2):131-9.

55. Sarkisian CA, Prohaska TR, Mangione CM. Older adults with low expectations for aging are less likely to participate in phyiscal activity. J Gen Intern Med. 2003;18(S1):199.

56. Sarkisian CA, Hays RD, Mangione CM. Do older adults expect to age successfully? The association between expectations regarding aging and beliefs regarding healthcare seeking among older adults. J Am Geriatr Soc. 2002;50(11):1837-43.

57. Weiner B. An attributional theory of achievement motivation and emotion. Psychol Rev. 1985;92(4):548-73.

58. Weiner B. Human motivation: metaphors, theories, and research. Newbury Park: Sage; 1992

59. Weiner B. An attributional theory of motivation and emotion. New York: Springer-Verlag; 1986.

60. Piedra LM, Andrade FCD, Hernandez R, Boughton SW, Trejo L, Sarkisian CA. The influence of exercise on cognitive function in older Hispanic/ Latino adults: results from the " ¡Caminemos!" study. The Gerontologist. 2017;57(6):1072-83.

61. Callahan CM, Unverzagt FW, Hui SL, Perkins AJ, Hendrie HC. Six-item screener to identify cognitive impairment among potential subjects for clinical research. Med Care. 2002;40(9):771-81.

62. Belza B, Snyder S, Thompson M, LoGerfo J. From research to practice: EnhanceFitness, an innovative community-based senior exercise program. Top Geriatric Rehabil. 2010;26(4):299-309.

63. Gawronski B, Bodenhausen GV. Associative and propositional processes in evaluation: an integrative review of implicit and explicit attitude change. Psychol Bull. 2006;132(5):692-731.

64. Wilson TD, Dunn DS, Kraft D, Lisle DJ: Introspection, attitude change, and attitude-behavior consistency: the disruptive effects of explaining why we feel the way we do. In: Advances in Experimental Social Psychology, edn. Edited by Leonard B: Academic Press; 1989;22:287-343.

65. Guralnik JM, Ferrucci L, Pieper CF, Leveille SG, Markides KS, Ostir GV, Studenski S, Berkman LF, Wallace RB. Lower extremity function and subsequent disability: consistency across studies, predictive models, and value of gait speed alone compared with the short physical performance battery. J Gerontol A Biol Sci Med Sci. 2000;55(4):M221-31.

66. Guralnik JM, Simonsick EM, Ferrucci L, Glynn RJ, Berkman LF, Blazer DG, Scherr PA, Wallace RB. A short physical performance battery assessing lower extremity function: association with self-reported disability and prediction of mortality and nursing home admission. J Gerontol. 1994;49(2):M85-94.

67. Guralnik JM, Ferrucci L, Simonsick EM, Salive ME, Wallace RB. Lowerextremity function in persons over the age of 70 years as a predictor of subsequent disability. N Engl J Med. 1995;332(9):556-61. 
68. Tudor-Locke C. A preliminary study to determine instrument responsiveness to change with a walking program: physical activity logs versus pedometers. Res Q Exerc Sport. 2001;72(3):288-92.

69. Bassett DRAB, Leggett SR, Mathien CA, Main JA, Hunter DC, Duncan GE. Accuracy of five electronic pedometers for measuring distance walked. Med Sci Sports Exerc. 1996:28:1071-7.

70. Welk GJ, Differding JA, Thompson RW, Blair SN, Dziura J, Hart P. The utility of the Digi-walker step counter to assess daily physical activity patterns. Med Sci Sports Exerc. 2000;32(9 Suppl):S481-8.

71. Dipietro L, Caspersen CJ, Ostfeld AM, Nadel ER. A survey for assessing physical activity among older adults. Med Sci Sports Exerc. 1993;25(5):628-642.

72. De Abajo S, Larriba R, Marquez S. Validity and reliability of the Yale physical activity survey in Spanish elderly. J Sports Med Phys Fitness. 2001;41(4):479-85.

73. Sarkisian CA, Hays RD, Berry S, Mangione CM. Development, reliability, and validity of the expectations regarding aging (ERA-38) survey. The Gerontologist. 2002;42(4):534-42.

74. Sarkisian CA, Steers WN, Hays RD, Mangione CM. Development of the 12-item expectations regarding aging survey. The Gerontologist. 2005;45(2):240-8.

75. Levy BR, Slade MD, Murphy TE, Gill TM. Association between positive age stereotypes and recovery from disability in older persons. JAMA. 2012;308(19):1972-3.

76. Levy BR, Slade MD, Kunkel SR, KasI SV. Longevity increased by positive selfperceptions of aging. J Pers Soc Psychol. 2002;83(2):261.

77. Levy BR. Mind matters: cognitive and physical effects of aging selfstereotypes. J Gerontol Ser B Psychol Sci Soc Sci. 2003;58(4):P203-11.

78. Lorig K, Stewart A, Ritter P, Gonzalez V, Laurent D, Lynch J. Outcome measures for health education and other health care interventions. Thousand Oaks: Sage Publications, Inc.; 1996.

79. Resnick B, Zimmerman SI, Orwig D, Furstenberg AL, Magaziner J. Outcome expectations for exercise scale: utility and psychometrics. J Gerontol Ser B Psychol Sci Soc Sci. 2000;55(6):S352-6.

80. Williams DM, Anderson ES, Winett RA. A review of the outcome expectancy construct in physical activity research. Ann Behav Med. 2005;29(1):70-9.

81. Katz JN, Chang LC, Sangha O, Fossel AH, Bates DW. Can comorbidity be measured by questionnaire rather than medical record review? Med Care. 1996;34(1):73-84.

82. Ware J Jr, Kosinski M, Keller SD. A 12-item short-form health survey: construction of scales and preliminary tests of reliability and validity. Med Care. 1996;34(3):220-33.

83. Turner-Bowker D, Hogue SJ. Short form 12 health survey (SF-12). In: Michalos AC, editor. Encyclopedia of Quality of Life and Well-Being Research. Edn. Dordrecht: Springer Netherlands; 2014. p. 5954-7.

84. Sam DL, Berry JW. Acculturation: when individuals and groups of different cultural backgrounds meet. Perspect Psychol Sci. 2010;5(4):472-81.

85. Berry JW. A psychology of immigration. J Soc Issues. 2001;57(3):615-31.

86. Marin G, Sabogal F, Marin BV, Otero-Sabogal R, Perez-Stable EJ. Development of a short acculturation scale for Hispanics. Hisp J Behav Sci. 1987;9(2):183-205.

87. McCulloch CE, Searle SR: Linear mixed models (LMMs). In: Generalized, Linear, and Mixed Models. Edn.: John Wiley \& Sons, Inc.; 2000: 156-186.

88. Verbeke G. Linear mixed models for longitudinal data. In: Verbeke G, Molenberghs G, editors. Linear Mixed Models in Practice: A SASOriented Approach. New York: Springer New York; 1997. p. 63-153.

89. Tudor-Locke C, Craig CL, Aoyagi Y, Bell RC, Croteau KA, De Bourdeaudhuij I, Ewald B, Gardner AW, Hatano Y, Lutes LD. How many steps/day are enough? For older adults and special populations. Int J Beh Nutr Phys Act. 2011;8(1):80.

90. Hernandez R, Kershaw KN, Prohaska TR, Wang PC, Marquez DX Sarkisian CA. The cross-sectional and longitudinal association between perceived neighborhood walkability characteristics and depressive symptoms in older Latinos: the "iCaminemos!" study. J Aging Health. 2015;27(3):551-68.

91. Penedo FJ, Dahn JR. Exercise and well-being: a review of mental and physical health benefits associated with physical activity. Curr Opin Psychiatry. 2005;18(2):189-93.

92. Taylor A, Cable N, Faulkner G, Hillsdon M, Narici M, Van Der Bij A. Physical activity and older adults: a review of health benefits and the effectiveness of interventions. J Sports Sci. 2004;22(8):703-25.
93. Hernandez R, Andrade FCD, Piedra LM, Tabb KM, Xu S, Sarkisian C. The impact of exercise on depressive symptoms in older Hispanic/Latino adults: results from the ' $; C$ aminemos!' study. Aging Ment Health. 2018:1-6.

94. Mothes H, Leukel C, Jo HG, Seelig H, Schmidt S, Fuchs R. Expectations affect psychological and neurophysiological benefits even after a single bout of exercise. J Behav Med. 2017:40(2):293-306.

95. McAuley E, Morris KS, Motl RW, Hu L, Konopack JF, Elavsky S. Long-term follow-up of physical activity behavior in older adults. Health Psychol. 2007;26(3):375.

96. Desharnais R, Bouillon J, Godin G. Self-efficacy and outcome expectations as determinants of exercise adherence. Psychol Rep. 1986:59(3):1155-9.

97. Wurm S, Warner LM, Ziegelmann JP, Wolff JK, Schüz B. How do negative self-perceptions of aging become a self-fulfilling prophecy? Psychol Aging. 2013;28(4):1088

98. Hausdorff JM, Levy BR, Wei JY. The power of ageism on physical function of older persons: reversibility of age-related gait changes. J Am Geriatr Soc. 1999:47(11):1346-9.

99. Wolff JK, Warner LM, Ziegelmann JP, Wurm S. What do targeting positive views on ageing add to a physical activity intervention in older adults? Results from a randomised controlled trial. Psychol Health. 2014;29(8):915-32.

100. Cuddy A. Presence: bringing your boldest self to your biggest challenges. New York: Hachette; 2015.

101. Marquez DX, Wilbur J, Hughes SL, Berbaum ML, Wilson RS, Buchner DM, McAuley E. B.A.I.L.a. - a Latin dance randomized controlled trial for older Spanish-speaking Latinos: rationale, design, and methods. Contemp Clin Trials. 2014;38(2):397-408.

102. Glasgow RE, Vogt TM, Boles SM. Evaluating the public health impact of health promotion interventions: the RE-AIM framework. Am J Public Health. 1999;89(9):1322-7.

103. Glasgow RE, Klesges LM, Dzewaltowski DA, Estabrooks PA, Vogt TM. Evaluating the impact of health promotion programs: using the RE-AIM framework to form summary measures for decision making involving complex issues. Health Educ Res. 2006;21(5):688-94.

104. Gaglio B, Shoup JA, Glasgow RE. Am J Public Health. 2013;103(6):e38-46.

105. The RE-AIM. Framework: a systematic review of use over time Le GM, Tudor-Locke C: comparison of pedometer and accelerometer accuracy under controlled conditions. Med Sci Sports Exerc. 2003;35(5):867-71.

106. Cyarto EV, Myers A, Tudor-Locke C. Pedometer accuracy in nursing home and community-dwelling older adults. Med Sci Sports Exerc. 2004;36(2):205-9.

\section{Ready to submit your research? Choose BMC and benefit from:}

- fast, convenient online submission

- thorough peer review by experienced researchers in your field

- rapid publication on acceptance

- support for research data, including large and complex data types

- gold Open Access which fosters wider collaboration and increased citations

- maximum visibility for your research: over $100 \mathrm{M}$ website views per year

At $\mathrm{BMC}$, research is always in progress.

Learn more biomedcentral.com/submissions 